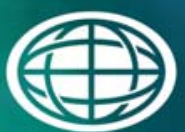

Savannah River

National Laboratory ${ }^{m}$

OPERATED BY SAVANNAH RIVER NUCLEAR SOLUTIONS

\title{
Sample Results from MCU Solids Outage
}

\section{T. B. Peters}

A. L. Washington, II

L. N. Oji

C. J. Coleman

M. R. Poirier

September 2014

SRNL-STI-2014-00336, Revision 0 


\section{DISCLAIMER}

This work was prepared under an agreement with and funded by the U.S. Government. Neither the U.S. Government or its employees, nor any of its contractors, subcontractors or their employees, makes any express or implied:

1. warranty or assumes any legal liability for the accuracy, completeness, or for the use or results of such use of any information, product, or process disclosed; or

2. representation that such use or results of such use would not infringe privately owned rights; or

3. endorsement or recommendation of any specifically identified commercial product, process, or service.

Any views and opinions of authors expressed in this work do not necessarily state or reflect those of the United States Government, or its contractors, or subcontractors.

\section{Printed in the United States of America}

Prepared for

U.S. Department of Energy 
Keywords: $M C U, A R P, I S D P$

Retention: Permanent

\section{Sample Results from MCU Solids Outage}

T. B. Peters

A. L. Washington, II

L. N. Oji

C. J. Coleman

M. R. Poirier

September 2014

Prepared for the U.S. Department of Energy under contract number DE-AC09-08SR22470.

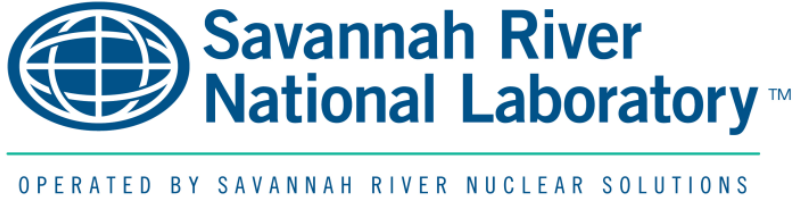




\section{REVIEWS AND APPROVALS}

\section{AUTHORS:}

T. B. Peters, Author, Advanced Characterization and Processing

Date

A. L. Washington, II, Co-author, Advanced Characterization and Processing Date

L. N. Oji, Co-author, Advanced Characterization and Processing Date

C. J. Coleman, Co-author, Analytical Development Date

M. R. Poirier, Co-author, Advanced Characterization and Processing

Date

TECHNICAL REVIEW: (Reviewed per E7 2.60)

C. A. Nash, Technical Reviewer, Advanced Characterization and Processing

Date

\section{APPROVAL:}

F. M. Pennebaker, Manager, Advanced Characterization and Processing

Date

S. L. Marra, Manager, E\&CPT Research Programs

Date

D. J. Martin, Manager, Tank Farm Facility Engineering

Date 


\section{EXECUTIVE SUMMARY}

Savannah River National Laboratory (SRNL) has received several solid and liquid samples from MCU in an effort to understand and recover from the system outage starting on April 6, 2014.

SRNL concludes that the presence of solids in the Salt Solution Feed Tank (SSFT) is the likely root cause for the outage, based upon the following discoveries

- A solids sample from the extraction contactor \#1 proved to be mostly sodium oxalate

- A solids sample from the scrub contactor\#1 proved to be mostly sodium oxalate

- A solids sample from the Salt Solution Feed Tank (SSFT) proved to be mostly sodium oxalate

- An archived sample from Tank $49 \mathrm{H}$ taken last year was shown to contain a fine precipitate of sodium oxalate

- A solids sample from the extraction contactor \#1 drain pipe from extraction contactor\#1 proved to be mostly sodium aluminosilicate

- A liquid sample from the SSFT was shown to have elevated levels of oxalate anion compared to the expected concentration in the feed

Visual inspection of the SSFT indicated the presence of precipitated or transferred solids, which were likely also in the Salt Solution Receipt Tank (SSRT). The presence of the solids coupled with agitation performed to maintain feed temperature resulted in oxalate solids migration through the MCU system and caused hydraulic issues that resulted in unplanned phase carryover from the extraction into the scrub, and ultimately the strip contactors. Not only did this carryover result in the Strip Effluent (SE) being pushed out of waste acceptance specification, but it resulted in the deposition of solids into several of the contactors. At the same time, extensive deposits of aluminosilicates were found in the drain tube in the extraction contactor \#1. However it is not known at this time how the aluminosilicate solids are related to the oxalate solids.

The solids were successfully cleaned out of the MCU system. However, future consideration must be given to the exclusion of oxalate solids into the MCU system. 
There were 53 recommendations for improving operations recently identified. Some additional considerations or additional details are provided below as recommendations.

- From this point on, IC-Anions analyses of the DSSHT should be part of the monthly routine analysis in order to spot negative trends in the oxalate leaving the MCU system. Care must be taken to monitor the oxalate content to watch for sudden precipitation of oxalate salts in the system.

- Conduct a study to optimize the cleaning strategy at ARP-MCU through decreasing the concentration or entirely eliminating the oxalic acid.

- The contents of the SSFT should remain unagitated. Routine visual observation should be maintained to ensure there is not a large buildup of solids. As water with agitation provided sufficient removal of the solids in the feed tank, it should be considered as a good means for dissolving oxalate solids if they are found in the future.

- Conduct a study to improve prediction of oxalate solubility in salt batch feed materials. As titanium and mercury have been found in various solids in this report, evaluate if either element plays a role in oxalate solubility during processing.

- Salt batch characterization focuses primarily on characterization and testing of unaltered Tank 21H material; however, non-typical feeds are developed through cleaning, washing, and/or sump transfers. As these solutions are processed through MCU, they may precipitate solids or reduce performance. Salt batch characterization and testing should be expanded to encompass a broader range of feeds that may be processed through ARPMCU. 


\section{LIST OF ABBREVIATIONS}

\begin{tabular}{|c|c|}
\hline $\mathrm{AD}$ & Analytical Development \\
\hline ARP & Actinide Removal Process \\
\hline CDT & Contactor Drain Tank \\
\hline CSEM & Contained Scanning Electron Microscopy \\
\hline CSS & Clarified Salt Solution \\
\hline CXRD & Contained X-Ray Diffraction \\
\hline DSS & Decontaminated salt solution \\
\hline DSSHT & Decontaminated Salt Solution Hold Tank \\
\hline ESS & Extraction Scrub Strip \\
\hline IC & Ion Chromatography \\
\hline ICPES & Inductively-Coupled Plasma Emission Spectroscopy \\
\hline ISDP & Interim Salt Disposition Program \\
\hline LWHT & Late Wash Hold Tank \\
\hline LWPT & Late Wash Precipitate Tank \\
\hline MCU & Modular Caustic Side Solvent Extraction Unit \\
\hline MST & Monosodium titanate \\
\hline$\%$ RSD & Percent Relative Standard Deviation \\
\hline SE & Strip effluent \\
\hline SEHT & Strip Effluent Hold Tank \\
\hline SRNL & Savannah River National Laboratory \\
\hline SRR & Savannah River Remediation \\
\hline SSFT & Salt Solution Feed Tank \\
\hline SSRT & Salt Solution Receipt Tank \\
\hline TIC/TOC & Total Inorganic Carbon/Total Organic Carbon \\
\hline TTR & Task Technical Request \\
\hline TTQAP & Task Technical And Quality Assurance Plan \\
\hline
\end{tabular}




\section{Table of Contents}

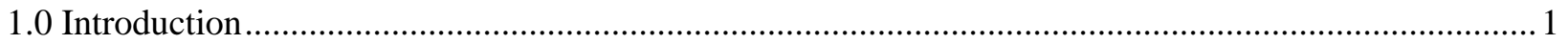

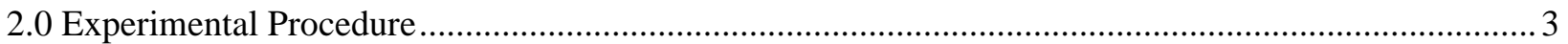

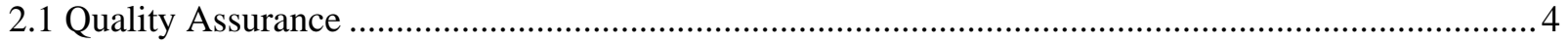

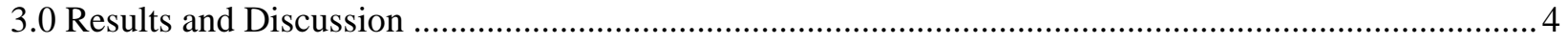

3.1 Results from DSSHT, SEHT and CDT Samples...................................................................... 4

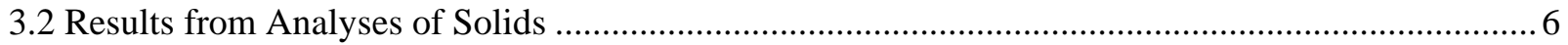

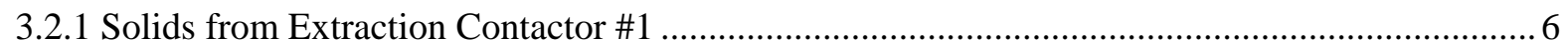

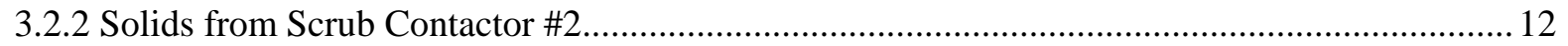

3.2.3 Solids from the Extraction Contactor \#1 Drain line .................................................................. 16

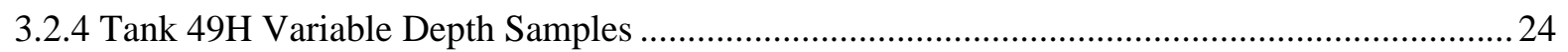

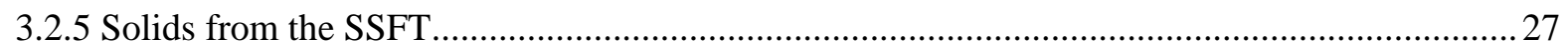

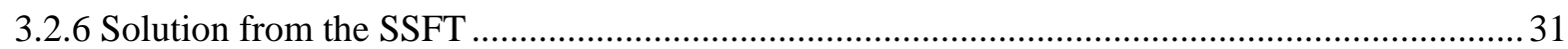

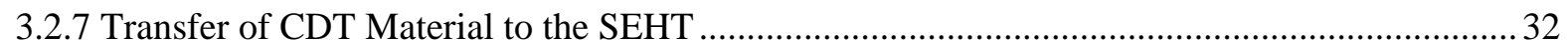

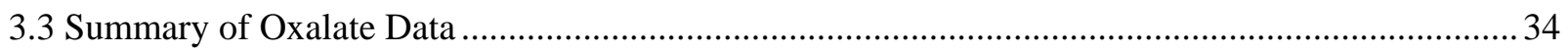

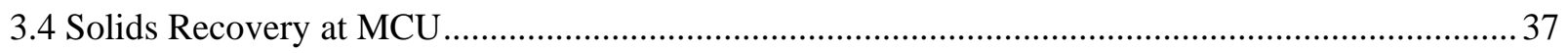

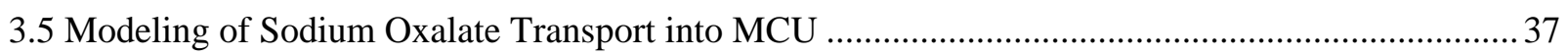

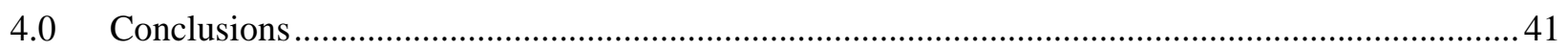

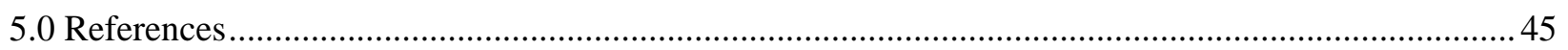




\section{List of Figures}

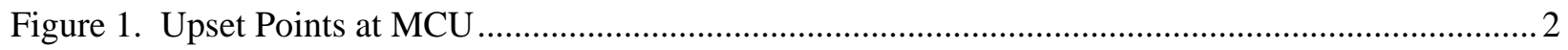

Figure 2. Solids from Extraction Contactor $\# 1$.............................................................................. 7

Figure 3. Solids from Extraction Contactor \#1 ….......................................................................... 7

Figure 4. CXRD of the Solids from Extraction Contactor \#1 ................................................................. 8

Figure 5. Typical CSEM Result from the Solids from Extraction Contactor \#1 ..................................... 9

Figure 6. Solids from Scrub Contactor \#2 …................................................................................. 12

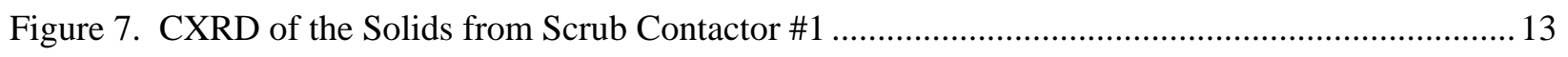

Figure 8. Typical CSEM Result from the Solids from Scrub Contactor \#1 ........................................... 14

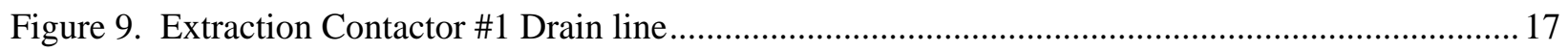

Figure 10. CXRD of the Solids from Extraction Contactor \#1 Drain Pipe.............................................. 18

Figure 11. Typical CSEM Result from the Extraction Contactor \#1 Drain Pipe...................................... 19

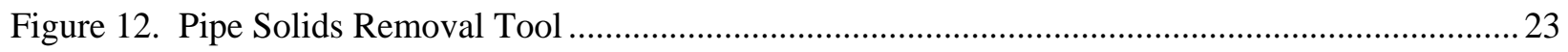

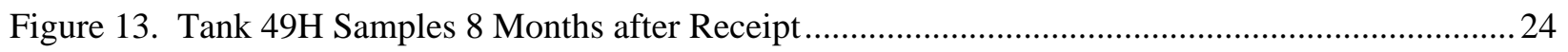

Figure 14. CXRD Result from HTF-E-167/168/169 Tank 49H Composite .............................................25

Figure 15. Typical CSEM Result from HTF-E-167/168/169 Tank 49H Composite ...............................26

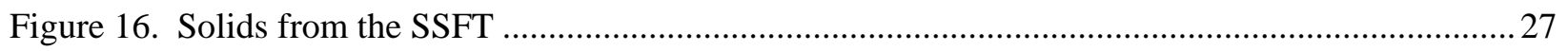

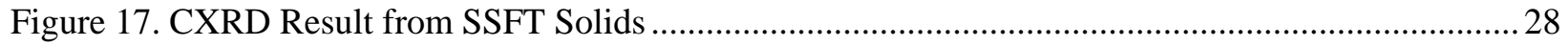

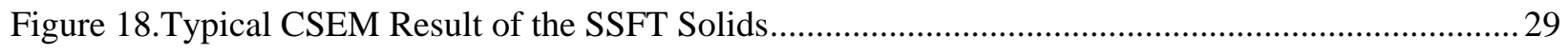

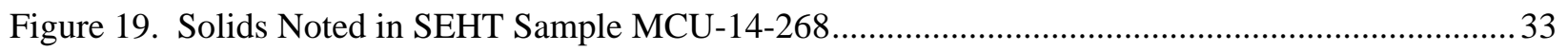

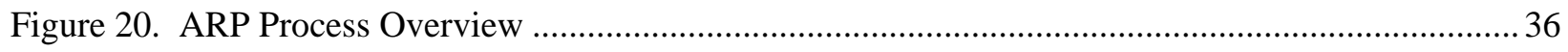

Figure 21. Typical Peak Attributed to Stainless Steel Fragments........................................................ 43

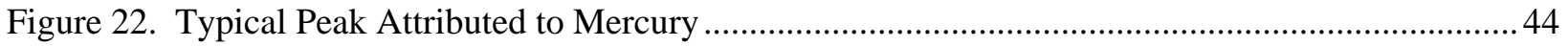




\subsection{Introduction}

At the Modular Caustic Side Solvent Extraction Unit (MCU), the changeover from the original solvent formulation to the new formulation was completed in November 2013, after extensive testing. ${ }^{1}$ During the January to March time period, the MCU was processing Salt Batch 6-D feed material. On March 19, the MCU was temporarily shut down for planned maintenance and to bring Salt Batch 7 into Tank 49. However, on April 6, attempts to restart the MCU failed, resulting in a process upset. In an effort to recover from the upset, solids were discovered in the MCU system. The major timeline of events leading up to, during and after recovery are as follows:

Jan-Feb contents of the SSRTs are mechanically agitated

April 6 failure to restart operations after small outage

April 6 additional restart attempts after troubleshooting mechanical components

April 12 nitric acid and water flushing of most contactors

April-June solids recovery efforts

April $7 \quad$ SEHT sample registers high $\mathrm{pH}(>11)$

April 23 CDT to SEHT transfer

April 25 solids observed in extraction and scrub contactor

April 28 solids from Extraction Contactor \#1 delivered

May 19 solids from Scrub Contactor \#2 delivered

May 27 Began Deinventory of SSFT and SSRTs

May $30 \quad$ Extraction Contactor\#1 Drain Pipe delivered

June $7 \quad$ video of inside of SSFT reveals high solids content

June 10 sample of solids from the SSFT delivered to SRNL

June 22 Initiated cleaning of SSRT and SSFT

July 7 routine operations restarted

The presence of the solids coupled with agitation performed to maintain feed temperature resulted in oxalate solids migration through the MCU system and caused hydraulic issues that resulted in unplanned phase carryover from the extraction into the scrub, and ultimately the strip contactors. Not only did this carryover result in the Strip Effluent (SE) sodium, Isopar, and $\mathrm{pH}$ being out of waste acceptance specification, but it resulted in the deposition of solids into several of the contactors. 
Figure 1. Upset Points at MCU

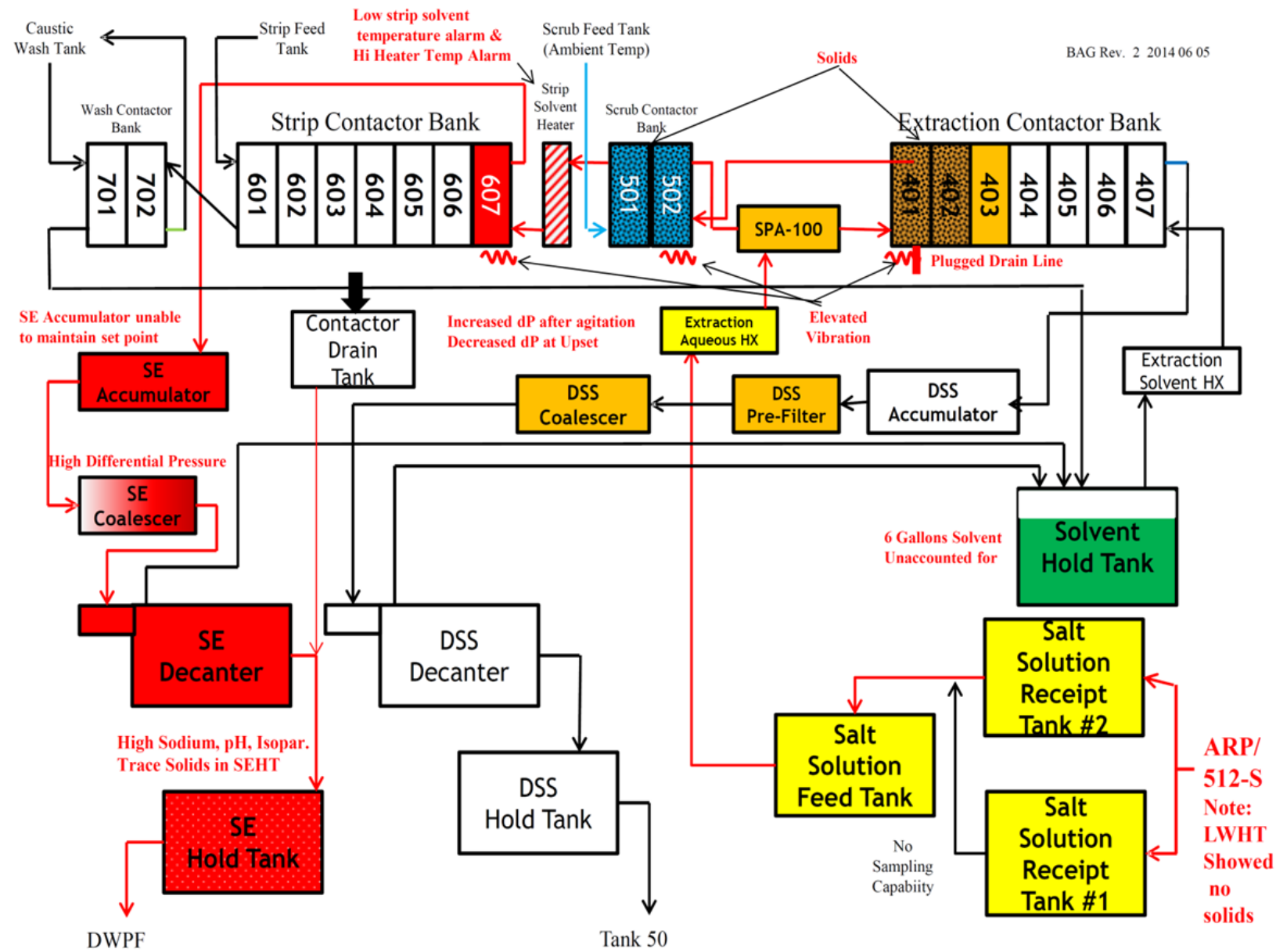

SRNL characterized a large number of MCU samples over a period of several months to help determine the nature of the precipitation problems. This report summarizes the results of the analyses of a number of the routine samples as well as process upset samples, which are summarized in this list:

- DSSHT and SEHT samples from April

- Samples from the Contactor Drain Tank (CDT)

- Solids from the extraction contactor\#1

- Solids from the scrub contactor\#2

- Solids from the extraction contactor \#1 drain pipe

- $\quad$ Solids from the Salt Solution Feed Tank (SSFT) 
In addition, this document discusses the investigation into the historical oxalate concentrations in the MCU system. This work was specified by Technical Task Request (TTR) ${ }^{2}$ and by Task Technical and Quality Assurance Plan (TTQAP). ${ }^{3}$ Details for the work are contained in controlled laboratory notebooks. ${ }^{4}$

\subsection{Experimental Procedure}

The DSSHT, SEHT, or Contactor Drain Tank (CDT) samples were contained in 10-mL P-nut vials. SEHT samples were delivered in doorstops for shielding purposes, while the DSSHT and CDT samples were delivered in thief holders. Samples were removed from the holders. In cases where there were multiple samples from the same point in time, the individual contents were composited into a single bottle. The DSSHT, SEHT, and CDT samples were sent for analysis without dilution or filtration. Samples of the solids were sent in metal containers except for the drain pipe solids which were shipped in the actual drain pipe.

When the extraction contactor\#1 drain pipe was received, the drain pipe was full of solids along an appreciable portion of its length and there was some question as to whether or not the solids in the pipe varied along the length. SRNL prepared a simple device that would core into the solids without disrupting the solids packing (see Figure 12 in section 3.2.3). The device employed a long drill bit with wide valleys which was drilled into the pipe, along the axis of solids. The first sample was drilled out of the solids at a 3" depth. The solids were then tapped out of the valleys into a wide sample pan. A second sample was drilled into the same hole and a sample was removed at $\sim 6$ ” depth. The solids were removed from the valleys and then a final sample was removed at $\sim 9$ " depth. There was no attempt to homogenize solids samples previous to submission for analysis.

Samples sent for solids digestion were digested either by hot aqua regia or sodium peroxide fusion. For the aqua regia method, approximately 1-1.25 grams of as-received wet solids were weighed into a Teflon pressure vessel designed for elevated temperature and pressure reactions. Concentrated hydrochloric acid $(9 \mathrm{~mL})$ and concentrated nitric acid $(3 \mathrm{~mL})$ were added to the pressure vessel and the vessel sealed. The vessel was heated to a temperature of $115^{\circ} \mathrm{C}$ for 2 hours in a conventional drying oven and then cooled to room temperature. The dissolution was diluted to a final volume of $50 \mathrm{~mL}$ with de-ionized water. For the sodium peroxide fusion, the wet samples were first dried by heating at $115^{\circ} \mathrm{C}$ to constant weight. Approximately 0.25 grams of dried sample was weighed into a zirconium crucible and followed by addition of 2.5 grams of sodium peroxide. This mixture was heated at $675{ }^{\circ} \mathrm{C}$ for 15 minutes in a muffle furnace. After cooling to near room temperature, the flux residue in the crucible was dissolved first with deionized water and then with concentrated nitric acid and these solutions diluted to a final volume of $250 \mathrm{~mL}$ with de-ionized water.

For samples that were water leached, approximately 1 gram of wet sample was suspended in water (either warm water or actively stirred) for 24 hours. Leaching inevitably did not dissolve the entire sample mass, but had the advantage of not destroying the anion content. 


\subsection{Quality Assurance}

Requirements for performing reviews of technical reports and the extent of review are established in manual E7 2.60. For SRNL documents, the extent and type of review using the SRNL Technical Report Design Checklist is outlined in WSRC-IM-2002-00011, Rev. 2. ${ }^{5}$

\subsection{Results and Discussion}

\subsection{Results from DSSHT, SEHT and CDT Samples}

The ${ }^{137}$ Cs results from the DSSHT, SEHT, and CDT analyses are listed in Table 1 . These samples were taken after the restart attempts in early April. Values in parentheses are analytical uncertainties. The source material entry was derived from a customer blend document for Salt Batch 7, and is used for comparison. ${ }^{6}$ Some of the CDT and SEHT data is previously reported but is included here for clarity. ${ }^{7}$

Table 1. Radiochemical Results for the DSSHT and SEHT Samples

\begin{tabular}{|c|c|c|c|}
\hline Sample ID & Sample Date & $\left.{ }^{\mathbf{1 3 7}} \mathbf{C s} \mathbf{( d p m} / \mathbf{m L}\right)$ & Sample Type \\
\hline MCU-14-230/231 & $4 / 10 / 2014$ & $1.72 \mathrm{E}+05(5.00 \%)$ & DSSHT \\
\hline MCU-14-233/236 & $4 / 10 / 2014$ & $1.44 \mathrm{E}+09(5.00 \%)$ & SEHT \\
\hline MCU-14-254/255 & $4 / 20 / 2014$ & $2.05 \mathrm{E}+06(5.00 \%)$ & CDT \\
\hline & & $1.02 \mathrm{E}+08$ & Source \\
\hline
\end{tabular}

The SEHT sample is displaying a ${ }^{137}$ Cs concentration typical of previous similar samples, although the DSSHT is noticeably higher than the January, February and March monthly samples. This is an indication that the cesium removal has either suffered from the presence of the solids, or a startup using CSS." Note that the restart problems occurred starting April 7, so the DSSHT, SEHT and CDT samples were after the problems started.

This is the first hot sample SRNL has received from the CDT. The CDT primary serves to collect the contents of the contactors (which can include dissolved solids and nitric acid), as well as sump material. This means that the contents of the CDT are poorly defined and can vary. In the case of this sample, the material in the CDT was a result of the draining of all the extraction, strip, and scrub contactors along with the acid flushing of the contactors.

\footnotetext{
* The values in the SEHT are relatively insensitive to changes in the decontamination factor, while the DSSHT value is more reflective of the Cs removal.
} 
The DSSHT, SEHT, and CDT samples were analyzed by Inductively Coupled Plasma Emission Spectroscopy (ICPES - see Table 2). Units are mg/L.

Table 2. ICPES Results for the DSSHT, SEHT, and CDT Samples

\begin{tabular}{|c|c|c|c|}
\hline Analyte & MCU-14-230/231 & MCU-14-233/236 & MCU-14-254/255 \\
\hline type & DSSHT (mg/L) & SEHT (mg/L) & CDT (mg/L) \\
\hline $\mathrm{Al}$ & 4150 & 93 & 411 \\
\hline $\mathrm{B}$ & 37.1 & 104 & 4.72 \\
\hline $\mathrm{Ca}$ & $<1.69$ & $<3.38$ & 15.9 \\
\hline $\mathrm{Cr}$ & 34.1 & $<3.26$ & 3.76 \\
\hline $\mathrm{K}$ & 248 & $<104$ & 24.7 \\
\hline $\mathrm{Na}$ & 96200 & 2550 & 11600 \\
\hline $\mathrm{P}$ & 141 & $<156$ & $<15.6$ \\
\hline $\mathrm{S}$ & 2140 & $<3000$ & $<300$ \\
\hline $\mathrm{Ti}$ & 4.83 & $<8.4$ & 40.6 \\
\hline $\mathrm{Zn}$ & 4.27 & $<3.96$ & 35.4 \\
\hline
\end{tabular}

The analytical uncertainty for the ICPES analysis is $10 \%$.

The DSSHT sample results are typical of this type of material and indicate dilution compared to the feed values. The SEHT values are notably different from typical SEHT results in that the aluminum and sodium values are much higher. Typically, previous SEHT samples have Al $<10$ $\mathrm{mg} / \mathrm{L}$ and $\mathrm{Na}$ of $\sim 50 \mathrm{mg} / \mathrm{L}$. In fact, the Na:Al ratio is typical of material of the DSSHT, indicating that it is probable that a small amount of material from the DSSHT has entered the SEHT, possibly on the order of $\sim 2 \%{ }^{\Upsilon}$

Without a historical precedent to compare to, the CDT sample results must be interpreted as a combination of material from any of the feed, DSS, SE, and/or cleaning solutions. Most of the results shown in the CDT results indicate a component of the feed or DSS (the ratios of these values are approximately the same as the feed and DSS). The titanium and zinc results are noticeably higher than feed or DSS. The high titanium value likely indicates dissolved titanium compounds. It is uncertain as to what to attribute the high zinc values to.

A select few of the DSSHT and SEHT samples, as well as the CDT sample were also analyzed by Ion Chromatography Anions (IC-Anions). See Table 3.

As with the ICPES results, the IC-Anions results for the DSSHT sample are typical of this type of material and shows signs of dilution compared to the feed values. For the SEHT sample, the

\footnotetext{
${ }^{\Upsilon}$ If all of the aluminum in the SEHT value is from uptake of DSS, then the approximate dilution of the SEHT is the ratio of the $\mathrm{Al}$ in the typical SEHT divided by the $\mathrm{Al}$ in the typical DSSHT result, which is $\sim 0.02$, or $2 \%$. Furthermore, as the boron value in the SEHT $(104 \mathrm{mg} / \mathrm{L})$ is almost exactly as predicted $(108 \mathrm{mg} / \mathrm{L})$, this implies any dilution of the SEHT is small.
} 
ratio of the nitrite to nitrate is further indication of a small amount ( $2 \%)$ of DSS incorporation into the SEHT.

The high concentration of oxalate in the CDT sample is an indication that the contactor cleaning has had some effect.

Table 3. IC-Anions Results for the DSSHT, SEHT, and CDT Samples (mg/L)

\begin{tabular}{|c|c|c|c|c|}
\hline Analyte & Salt Batch 7 Feed & MCU-14-230/231 & MCU-14-233/236 & MCU-14-254/255 \\
\hline type & estimate & DSSHT & SEHT & CDT \\
\hline F & 100 & $<500$ & $<50$ & $<10$ \\
\hline Formate & 649 & $<500$ & $<50$ & $<10$ \\
\hline Cl & 264 & $<500$ & $<50$ & 20 \\
\hline Nitrite & 33000 & 15000 & 377 & $<10$ \\
\hline $\mathrm{Br}$ & $\mathrm{NA}$ & $<500$ & $<50$ & $<50$ \\
\hline Nitrate & 148000 & 100000 & 2440 & 56200 \\
\hline Phosphate & 556 & $<500$ & $<50$ & $<10$ \\
\hline Sulfate & 9080 & 4540 & 111 & 602 \\
\hline oxalate & 392 & $<500$ & $<50$ & 6280 \\
\hline
\end{tabular}

The analytical uncertainty for the IC Anions analysis is $10 \%$.

\subsection{Results from Analyses of Solids}

As a result of the process interruption, a number of places in the MCU system were inspected for solids content, where ideally, there should be no solids. After extensive camera inspections, solid materials were removed from four places in the MCU system; extraction contactor \#1, scrub contactor \#1, the drain pipe for extraction contactor \#1, and the SSFT. All the solids arrived in metal containers, except the drain pipe solids which were shipped in the physical drain pipe.

\subsubsection{Solids from Extraction Contactor \#1}

A single sample container of solids from extraction contactor \#1 (MCU-14-274) arrived at SRNL on April 28. The solids had a pasty texture and were off-white in color (Figures 2 and 3). 


\section{Figure 2. Solids from Extraction Contactor \#1}

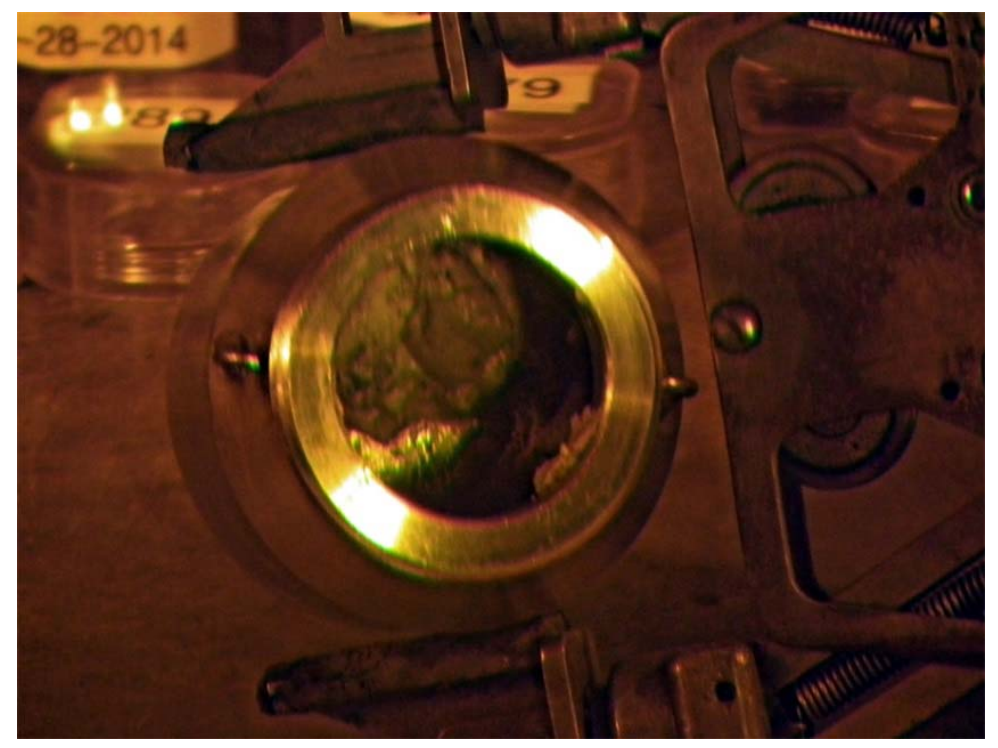

Figure 3. Solids from Extraction Contactor \#1

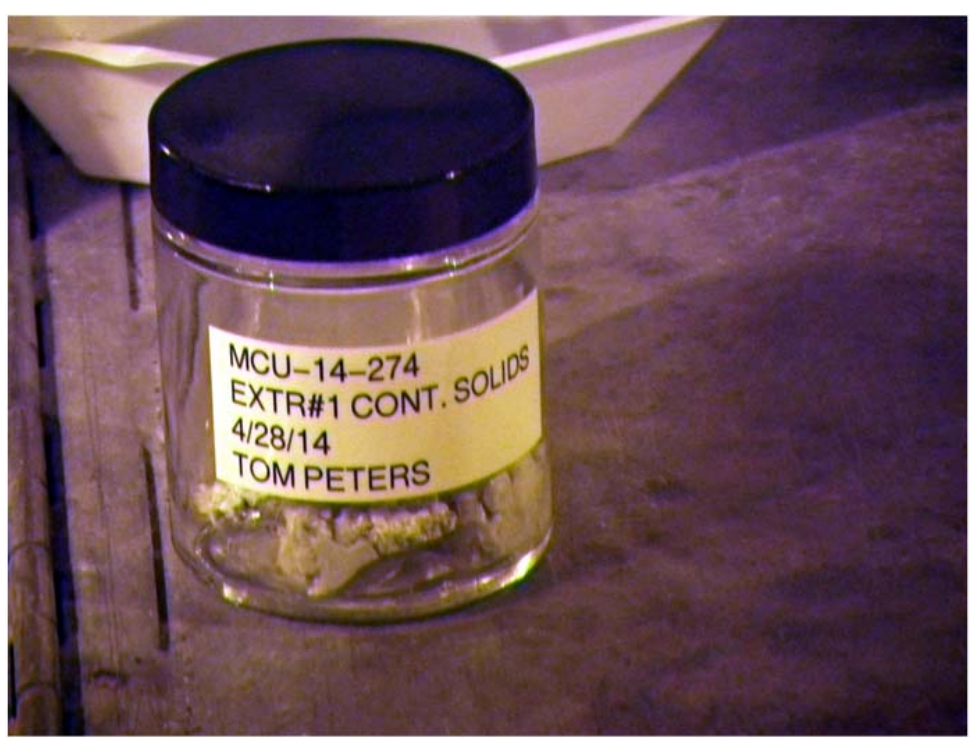

Samples of the solids were immediately sent to AD for Contained X-Ray Diffraction (CXRD) and Contained Scanning Electron Microscopy (CSEM). Figure 4 is the CXRD result, and shows sodium oxalate, sodium nitrate, and bayerite $\left(\mathrm{Al}(\mathrm{OH})_{3}\right)$. Notably absent was any aluminosilicate.

Figure 5 is one of many CSEM results for the sample, but one that is typical in appearance (small needles). Most of the solids are cylindrical in shape and most points register only sodium, carbon and oxygen. There are some spots registering titanium, and a few spots registering iron, chromium and nickel (stainless steel). There are very few, weak signals corresponding to either aluminum or silicon. 
Figure 4. CXRD of the Solids from Extraction Contactor \#1

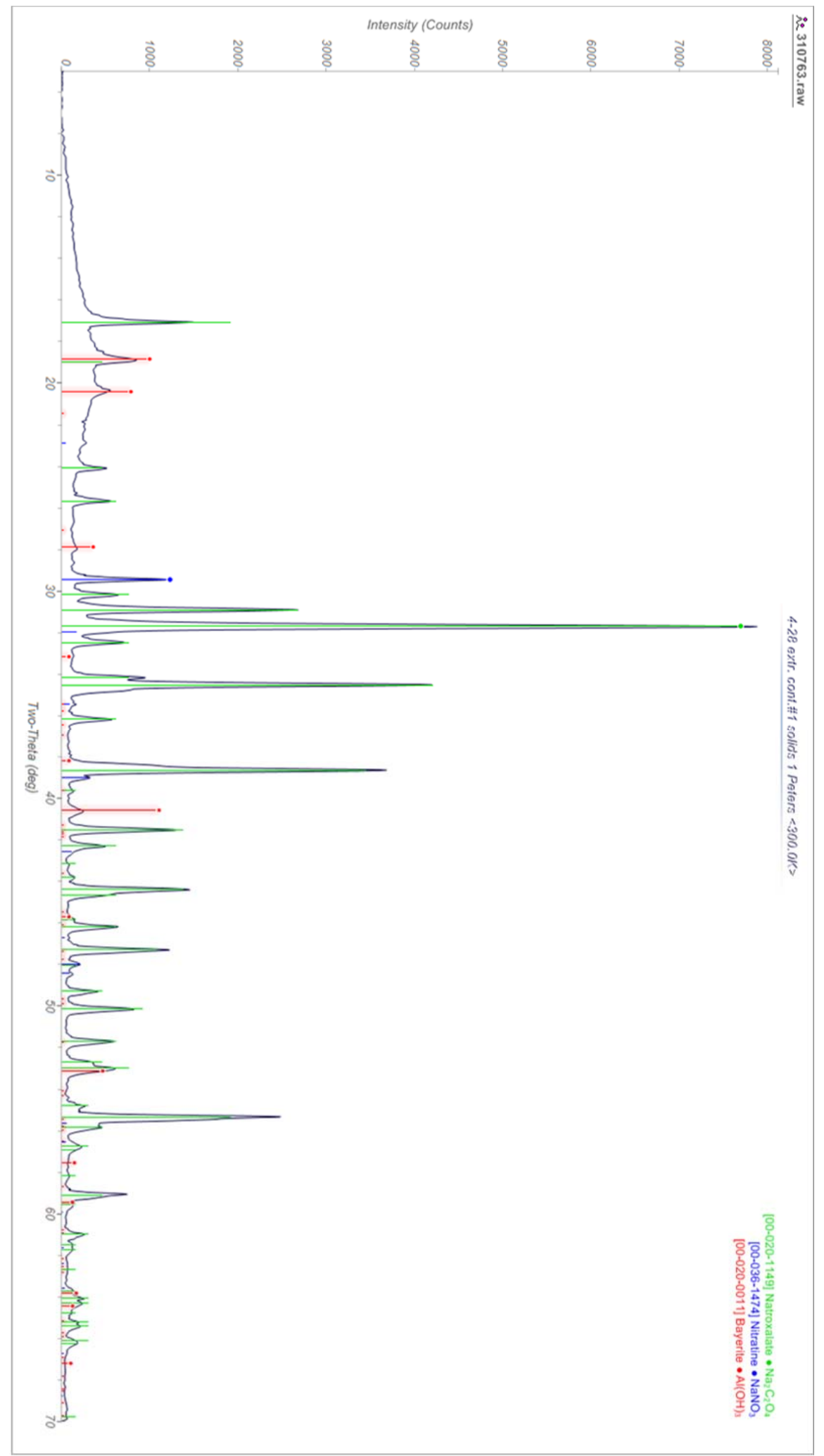


SRNL-STI-2014-00336

Revision 0

Figure 5. Typical CSEM Result from the Solids from Extraction Contactor \#1
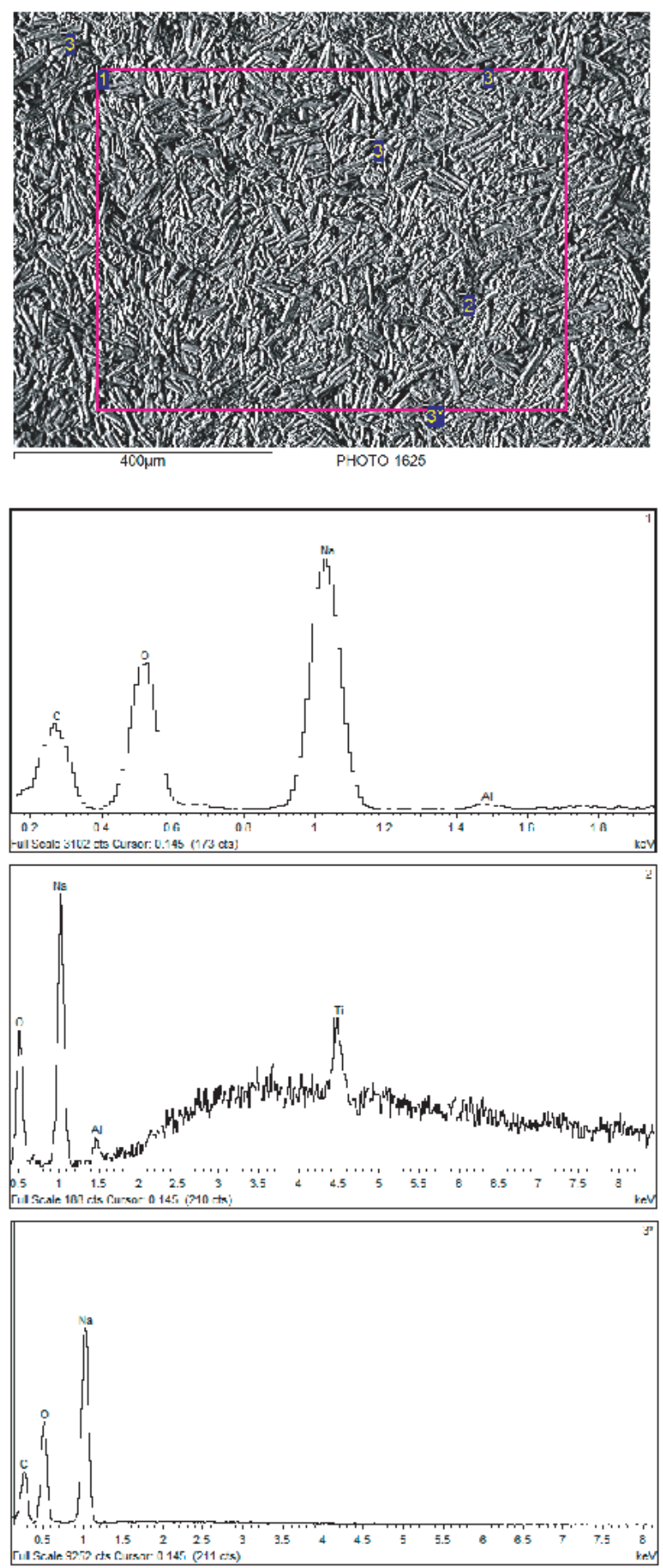
Two samples of the solids were digested in aqua regia, and the digestate from each was forwarded for ICPES analysis. Table 4 shows the average results for the two samples, with the value in parenthesis being the \% relative standard deviation (RSD). For the zinc result, the value is a single non less-than value. Due to concerns about lack of complete dissolution, a third sample underwent a sodium peroxide fusion digestion, followed by ICPES and wt\% total solids, the results of which are also listed in Table 4. The reader should note that the aqua regia sample is on a wet solids basis, while the sodium peroxide is on a dry weight basis.

Table 4. Results for the Digested Solids from Extraction Contactor \#1

\begin{tabular}{|c|c|c|}
\hline Analyte & Aqua regia $(\boldsymbol{\mu g} / \mathbf{g})$ & sodium peroxide fusion $(\boldsymbol{\mu g} / \mathbf{g})$ \\
\hline $\mathrm{Al}$ & $2020(13.7 \%)$ & 6570 \\
\hline $\mathrm{B}$ & $<240$ & $<92.9$ \\
\hline $\mathrm{Ca}$ & $191(14.8 \%)$ & $\mathrm{NA}^{\Pi}$ \\
\hline $\mathrm{Cr}$ & $130(7.61 \%)$ & $<181$ \\
\hline $\mathrm{K}$ & $<641$ & $<4350$ \\
\hline $\mathrm{Na}$ & $208000(11.9 \%)$ & $\mathrm{NA}$ \\
\hline $\mathrm{P}$ & $<960$ & $<2020$ \\
\hline $\mathrm{S}$ & $<18500$ & $<88500$ \\
\hline $\mathrm{Si}$ & $121(4.68 \%)$ & $<530$ \\
\hline $\mathrm{Ti}$ & $1018(14.2 \%)$ & 4460 \\
\hline $\mathrm{Zn}$ & 34.7 & $<88.5$ \\
\hline Total solids & $70.2 \%$ & $\mathrm{NA}$ \\
\hline
\end{tabular}

The analytical uncertainties for all analyses are $10 \%$. Units are $\mu \mathrm{g} / \mathrm{g}$, except for total solids.

For the aqua regia/ICPES, the relatively low $\mathrm{Al}$ and Si results compared to the Na results indicate that most of the solids are not due to aluminosilicate. However the low silicon value compared to $\mathrm{Al}$ suggests that aluminum hydroxide is a component of the solids, or that silicon in the solids is not fully dissolved. The sodium peroxide fusion digestion/ICPES clarifies the silicon value compared to $\mathrm{Al}$ and indicates that there is more aluminum hydroxide than aluminosilicate. The titanium is another indicator of titanium containing solids being present. The sodium peroxide fusion/ICPES indicates that the aqua regia did not dissolve most of the aluminum or titanium-containing solids, or that the samples are not homogenous in nature. The chromium and zinc are present in the feed, but likely present as small amounts of insoluble materials. The calcium value in the sodium peroxide fusion is compromised by the digestion method itself which tends to bring in tramp calcium.

Both the digestion methods destroy some of the anions, such as oxalate and nitrite, so IC-Anions analysis was not performed on those digested samples. In an attempt to determine the anion content of the solids, two further samples of the solids were dissolved through gentler means. In

\footnotetext{
$\Pi$ The sodium peroxide fusion compromises the Ca measurement.
} 
the first case, a sample was actively stirred in water at ambient temperature. In the second case, warm water was used to dissolve the solids. In both cases, there were small amounts of undissolved solids. Thus, the results do not completely reflect the entire composition, but only that of the dissolved part.

The solutions were sent for ICPES and IC-Anions analyses, the results of which are shown in Table 5. Both samples gave the same approximate results, indicating that either warm water or stirring did not entirely dissolve the solids, but those solids that did dissolve had the same approximate composition. The high sodium and oxalate results confirm that most of the solids are sodium oxalate. The aluminum and nitrate results corroborate the identification of sodium nitrate and aluminum hydroxide in the CXRD results (Figure 3 ). The titanium values are interesting - most titanium oxide type compounds do not readily dissolve in water. This may indicate that we have a water soluble form.

Table 5. IC-Anions and ICPES Results for the Dissolved Solids

\begin{tabular}{|c|c|c|}
\hline Analyte & Result $(\mu \mathrm{g} / \mathrm{g})$ & Result $(\mu \mathrm{g} / \mathrm{g})$ \\
\hline & Stirred water & Warm water \\
\hline $\mathrm{Al}$ & 503 & 402 \\
\hline $\mathrm{B}$ & 4.84 & 4.53 \\
\hline $\mathrm{Cr}$ & 10.9 & 9.41 \\
\hline $\mathrm{Fe}$ & 13.7 & 5.95 \\
\hline $\mathrm{K}$ & $<120$ & $<117$ \\
\hline $\mathrm{Na}$ & 217000 & 224000 \\
\hline $\mathrm{P}$ & 59.9 & 45.2 \\
\hline $\mathrm{S}$ & $<1850$ & $<1800$ \\
\hline Si & $<22$ & $<21.6$ \\
\hline $\mathrm{Ti}$ & 108 & 44.3 \\
\hline $\mathrm{Zn}$ & $<1.85$ & $<1.8$ \\
\hline $\mathrm{F}$ & $<926$ & $<902$ \\
\hline Formate & $<926$ & $<902$ \\
\hline $\mathrm{Cl}$ & $<926$ & $<902$ \\
\hline Nitrite & 2590 & 2570 \\
\hline $\mathrm{Br}$ & $<926$ & $<902$ \\
\hline Nitrate & 24300 & 24300 \\
\hline Phosphate & $<926$ & $<902$ \\
\hline Sulfate & $<4630$ & $<4510$ \\
\hline oxalate & 393000 & 401000 \\
\hline
\end{tabular}

The analytical uncertainty for all the analysis is $10 \%$. 
When compared to the more aggressive digestion results in Table 4, we note that the sodium value is about the same, while the aluminum and titanium results from the sodium peroxide fusion are higher. This indicates that most of the sodium salts dissolve readily, and while there are less soluble materials present, they represent a small fraction of the mass.

The average oxalate value of the two dissolutions in Table 5 is $397,000 \mu \mathrm{g} / \mathrm{g}$. The CXRD only identifies the sodium salt of oxalate. If there is $397,000 \mathrm{mg} / \mathrm{g}$ of oxalate, this requires 206,000 $\mu \mathrm{g} / \mathrm{g}$ of sodium. There is an average of $221,000 \mu \mathrm{g} / \mathrm{g}$ of sodium present, of which only a small amount is not related to oxalate. This leads to two conclusions. First, the vast majority of solids are from sodium oxalate (this assumes that only a small fraction of the solids remained undissolved). Second, from wt $\%$ total solids result in Table 4, we can then calculate that of the entire (wet) sample, $\sim 60 \%$ of the mass is sodium oxalate. ${ }^{f}$ From the information in Tables 4, 5 and the CXRD result in Figure 4, we can determine the bulk of the mass composition in the extraction contactor solids (Table 6).

Table 6. Approximate Mass Breakdown of Wet Solids from the Extraction Contactor

\begin{tabular}{|c|c|}
\hline Compound & wt\% of wet solids \\
\hline water & $30 \%$ \\
\hline Sodium oxalate & $60 \%$ \\
\hline Sodium nitrate & $3 \%$ \\
\hline remainder & $7 \%$ \\
\hline
\end{tabular}

\subsubsection{Solids from Scrub Contactor \#2}

A single sample container of solids from scrub contactor \#2 arrived at SRNL on May 19. The solids had a pasty texture and were off-white in color (Figure 6).

Figure 6. Solids from Scrub Contactor \#2

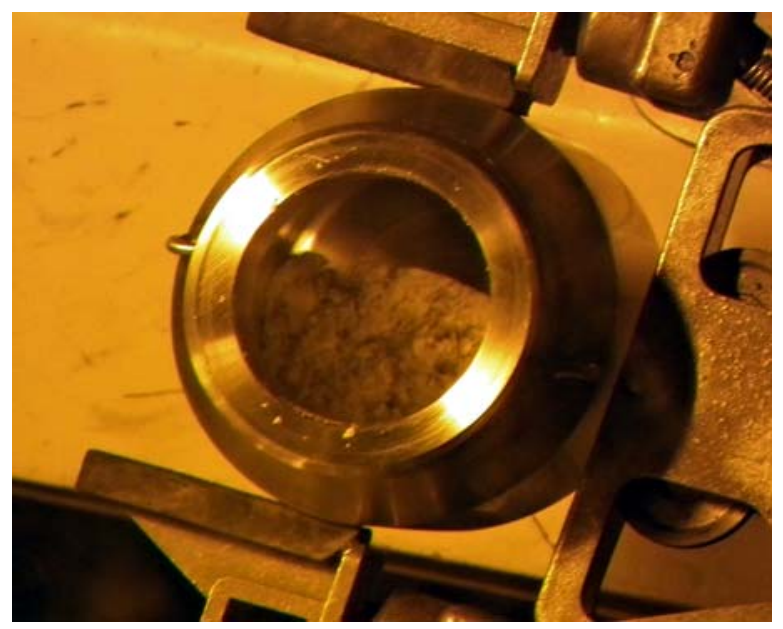

\footnotetext{
${ }^{f}$ The total $\mu \mathrm{g} / \mathrm{g}$ of sodium oxalate from Table 5 is $397,000+206,000=603,000 \mu \mathrm{g} / \mathrm{g}$, or $60.3 \%$ of the wet sample.
} 
Samples of the solids were immediately sent to AD for Contained X-Ray Diffraction (CXRD) and Contained Scanning Electron Microscopy (CSEM). Figure 7 is the CXRD result, and shows sodium oxalate, sodium nitrate, and $\mathrm{Al}(\mathrm{OH})_{3}$ (both Bayerite and Gibbsite). Gibbsite can be converted from Bayerite over time. Notably absent is any aluminosilicate.

Figure 7. CXRD of the Solids from Scrub Contactor \#1

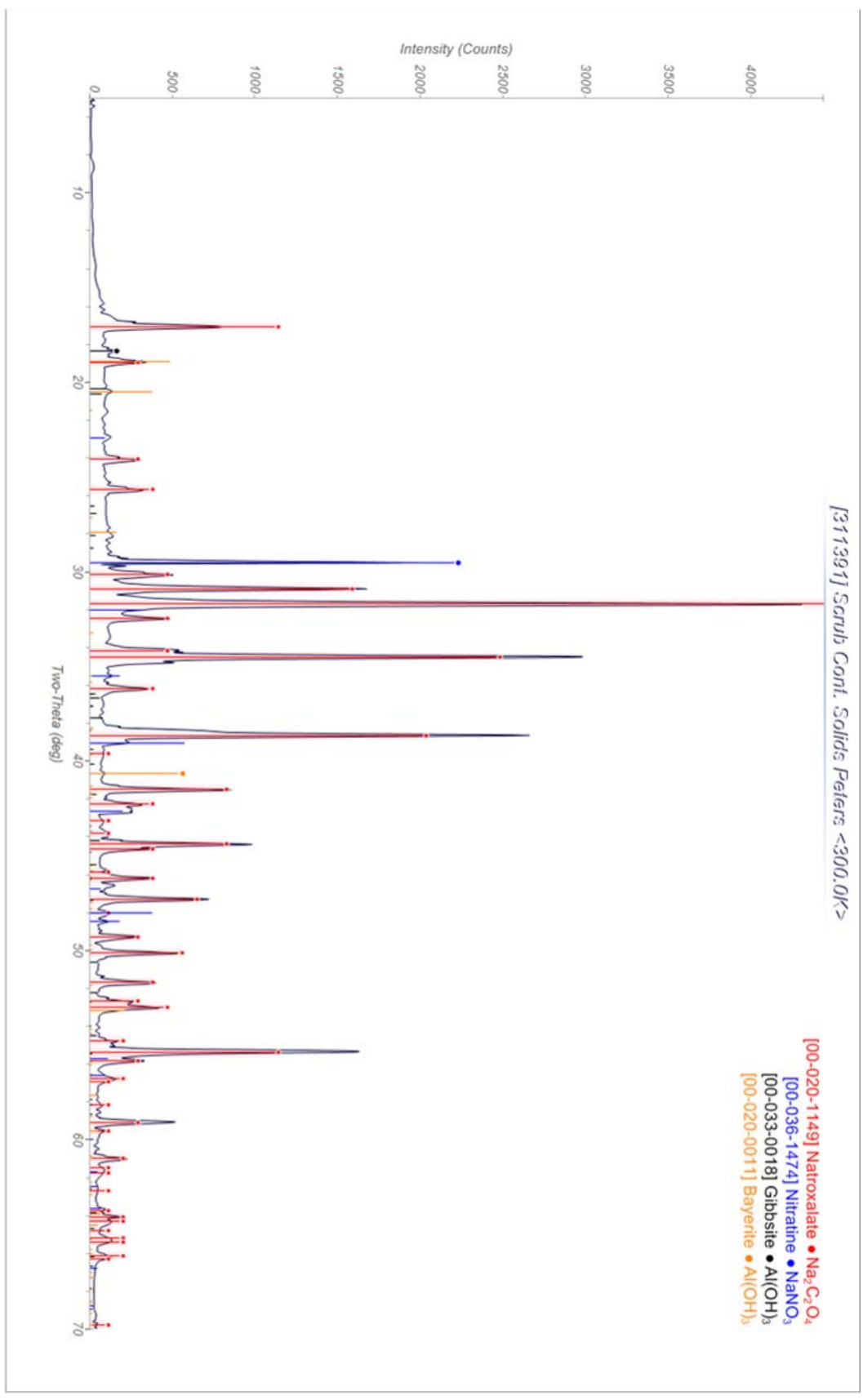


Figure 8 is one of many CSEM results for the sample, but one that is typical in appearance. Most of the solids are cylindrical in shape and most points register only sodium, carbon and oxygen (probably oxalate). There are some spots registering titanium, and a few spots registering iron, chromium and nickel (stainless steel). There are very few, weak signals corresponding to either aluminum or silicon. There are a few spots that register either mercury or uranium, from unknown compounds at this time. The uranium signal only showed up once, and at the same time, there was a signal for titanium. Thus, it is possible the uranium is bound to a titanium containing species.

\section{Figure 8. Typical CSEM Result from the Solids from Scrub Contactor \#1}
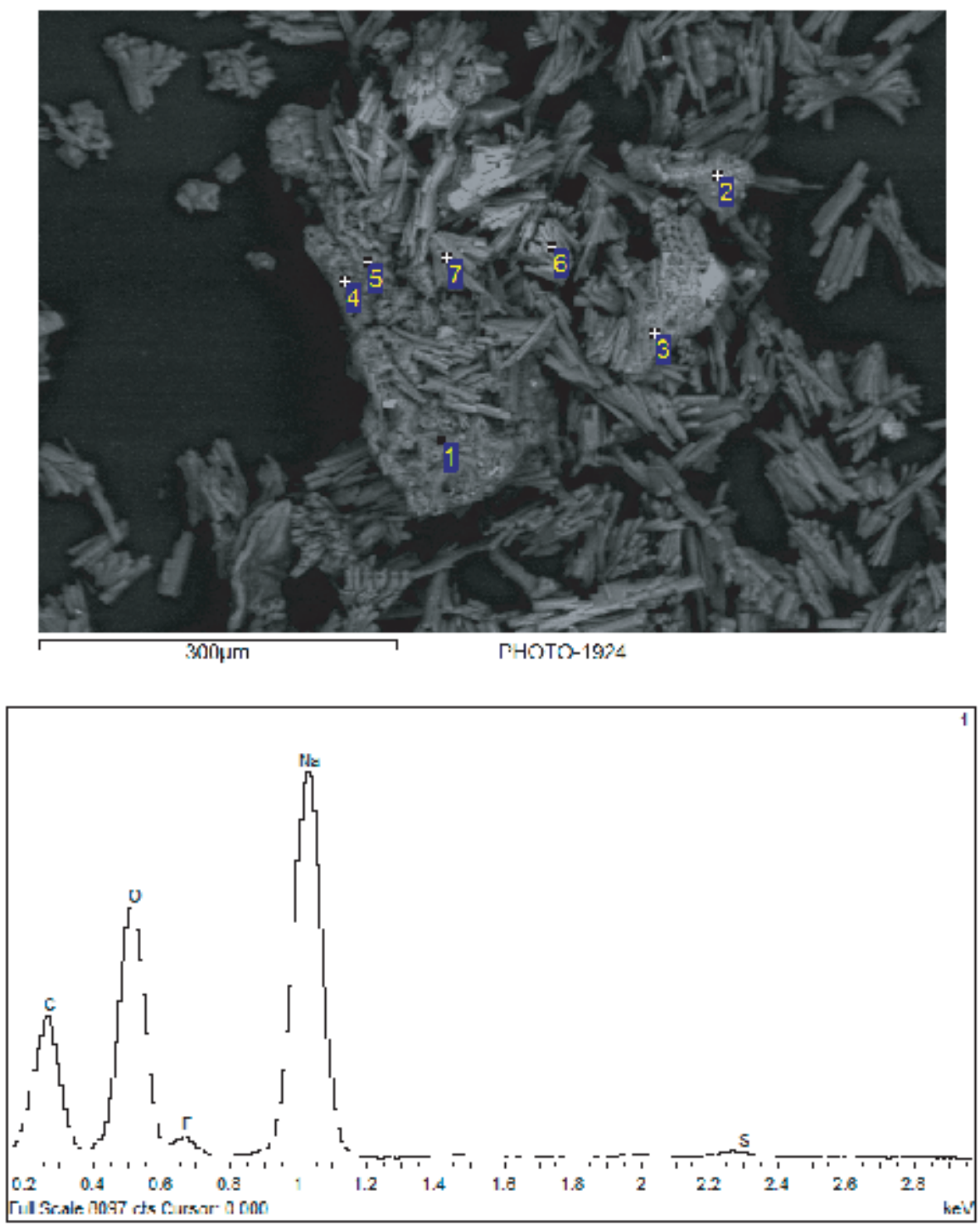
A sample of the solids was digested in aqua regia, and the digestate was forwarded for ICPES analysis. Table 7 shows the results for the sample.

\section{Table 7. ICPES Results for the Digested Solids from Scrub Contactor \#1}

\begin{tabular}{|c|c|}
\hline Analyte & Result $(\boldsymbol{\mu g} / \mathbf{g})$ \\
\hline $\mathrm{Al}$ & 2910 \\
\hline $\mathrm{B}$ & 14.5 \\
\hline $\mathrm{Cr}$ & 87.7 \\
\hline $\mathrm{Fe}$ & 314 \\
\hline $\mathrm{K}$ & 263 \\
\hline $\mathrm{Na}$ & 92100 \\
\hline $\mathrm{P}$ & 80.3 \\
\hline $\mathrm{S}$ & 1230 \\
\hline $\mathrm{Si}$ & 125 \\
\hline $\mathrm{Ti}$ & 642 \\
\hline $\mathrm{Zn}$ & 7.38 \\
\hline
\end{tabular}

The analytical uncertainty for the ICPES analysis is $10 \%$.

Although direct comparisons to the digested extraction contactor solids are made difficult due to the large number of less-than values (see Table 4), we can say that the analytes with the largest concentrations are the same (Al, Na, Ti). There is more sodium in the extraction contactor solids. Unfortunately, not enough sample was available for digestion by sodium peroxide fusion to provide a more complete dissolution of aluminum or silicon containing species.

A sample of the solids was dissolved at ambient temperature in water with stirring overnight. Again, while the majority of the solids dissolved, the solution was faintly cloudy which indicates some insoluble material was present. Therefore, the subsequent IC-Anions analysis may not accurately reflect the total solids composition. See Table 8 for the IC-Anions results. 
SRNL-STI-2014-00336

Revision 0

Table 8. IC-Anions Results for the Dissolved Solids

\begin{tabular}{|c|c|}
\hline Analyte & Result $(\boldsymbol{\mu g} / \mathbf{g})$ \\
\hline $\mathrm{F}$ & $<908$ \\
\hline Formate & $<908$ \\
\hline $\mathrm{Cl}$ & $<908$ \\
\hline Nitrite & 5539 \\
\hline $\mathrm{Br}$ & $<908$ \\
\hline Nitrate & 68100 \\
\hline Phosphate & $<908$ \\
\hline Sulfate & $<4540$ \\
\hline oxalate & 527000 \\
\hline
\end{tabular}

The analytical uncertainty for all the IC-Anions analysis is $10 \%$.

While the scrub contactor solids have the same major constituents as the extraction contactor solids, there are a higher proportion of nitrite and nitrate salts in the scrub contactor solids in the former. The high oxalate value should imply a larger sodium value $(\sim 274,000 \mu \mathrm{g} / \mathrm{g})$ in the ICPES results, assuming it is in the form of sodium oxalate. If some of the oxalate was present as oxalic acid, this would account for the lower than anticipated sodium content.

In summary, the solids from the scrub contactor are analyzed to be mostly sodium oxalate, with non-trivial amounts of sodium nitrate and aluminum hydroxide.

\subsubsection{Solids from the Extraction Contactor \#1 Drain line}

Once it was discovered that extraction contactor \#1 would not drain, the drain line was disconnected and sent to SRNL. The drain line arrived at SRNL on May 30. Visually, there was no obvious damage to the tube, but it was clearly packed with solids down on the flange end (Figure 9). The pipe was estimated to be anywhere from $1 / 3$ to $1 / 2$ full along the length, from the flange end. The flange end is the part that attaches to the drain valve, while the other end attaches to the extraction contactor.

The solids had a pasty texture and were off-white in color, similar in appearance to those found in the extraction and scrub contactors. 
Figure 9. Extraction Contactor \#1 Drain line

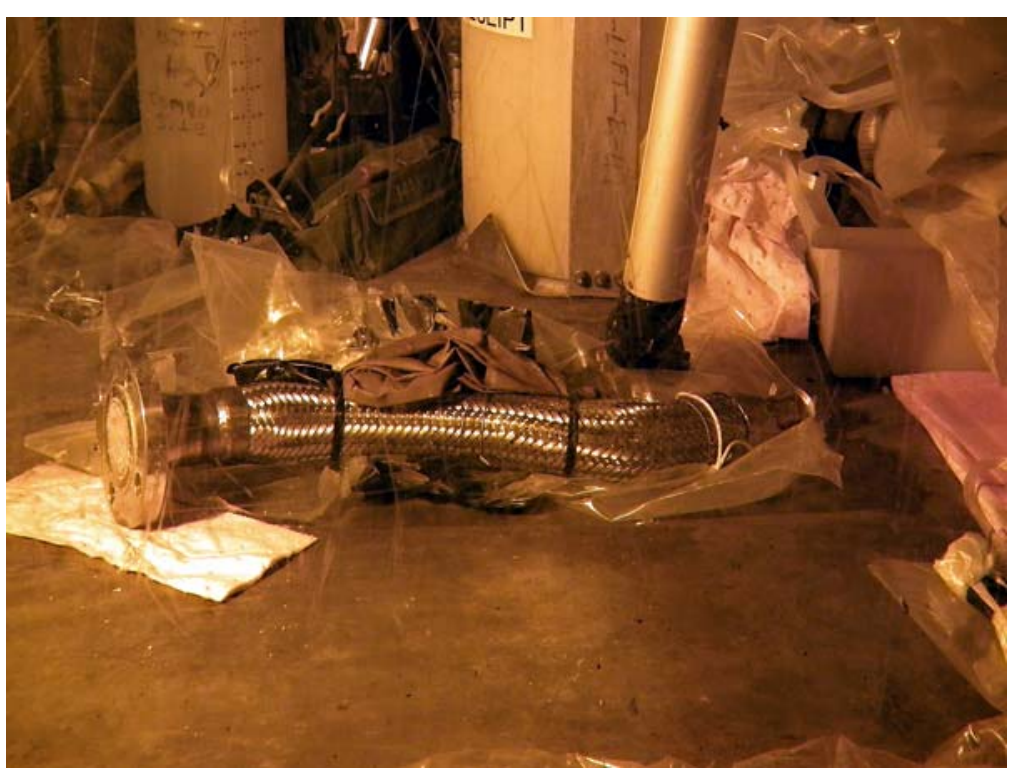

Samples of the solids were immediately sent to AD for Contained X-Ray Diffraction (CXRD) and Contained Scanning Electron Microscopy (CSEM). Figure 10 is the CXRD result, and shows only aluminosilicate ${ }^{\nabla}$ and sodium nitrate. This is somewhat surprising given that the both sets of contactor solids did not identify any aluminosilicate by CXRD; however, MCU facility had attempted to flush the contactor with nitric acid prior to the drain hose removal. Camera inspection after the flush revealed standing liquid, which was the first indicator that the drain line was plugged.

\footnotetext{
${ }^{\nabla}$ specifically the compound $\mathrm{Na}_{8}\left(\mathrm{Al}_{6} \mathrm{Si}_{6} \mathrm{O}_{24}\right)\left(\mathrm{NO}_{3}\right)_{2} \bullet 4 \mathrm{H}_{2} \mathrm{O}$, the only aluminosilicate identified throughout this document
} 
SRNL-STI-2014-00336

Revision 0

Figure 10. CXRD of the Solids from Extraction Contactor \#1 Drain Pipe

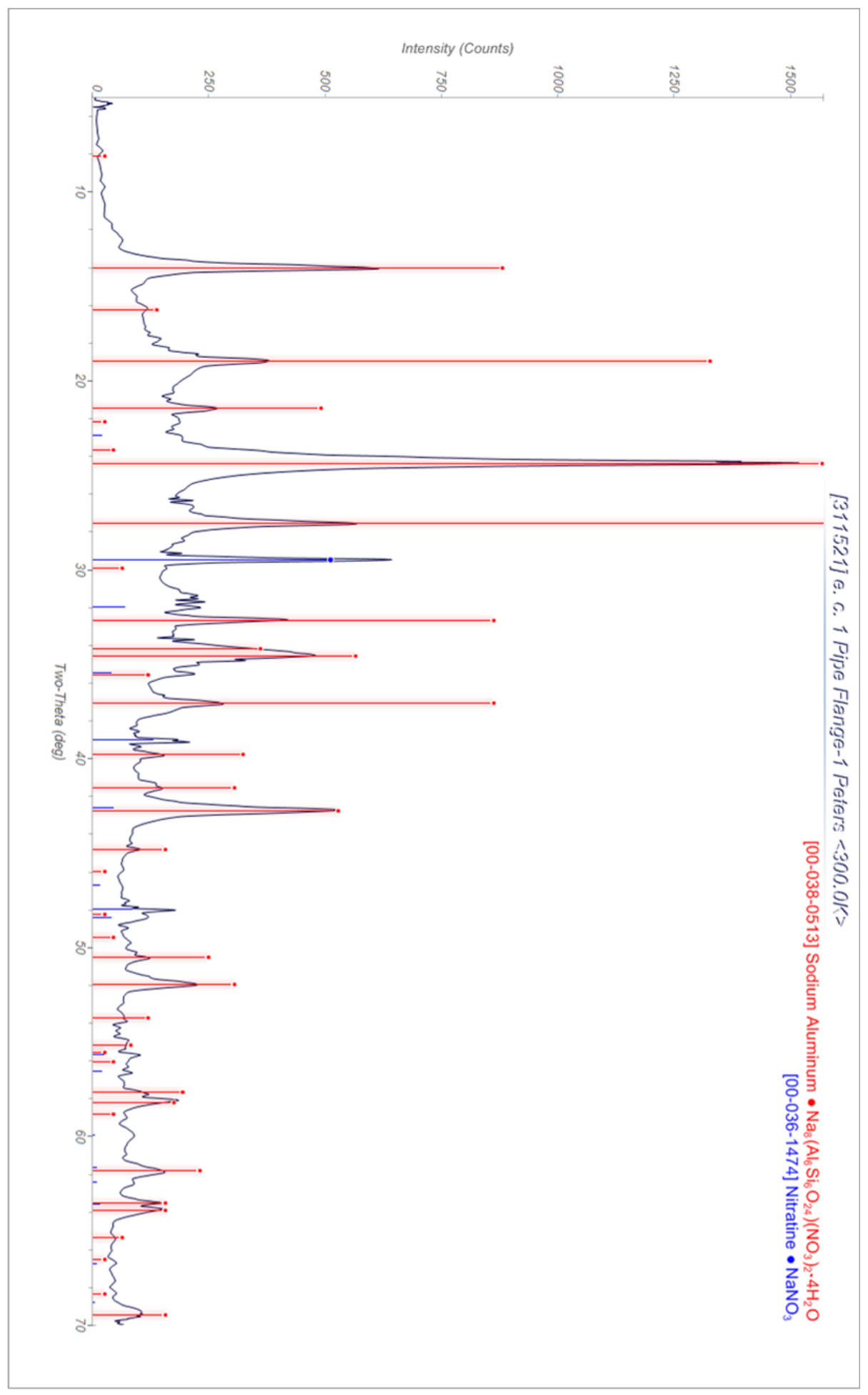


Figure 11 is one representative CSEM result for the sample. Most of the points register only aluminum, silicon (aluminosilicate), sodium, carbon and oxygen (possibly carbonate or oxalate). There are some spots registering titanium, and a few spots registering iron, chromium and nickel (stainless steel). There are a few spots that register either mercury or tin. It has been suggested the tin is due to pipe solder.

\section{Figure 11. Typical CSEM Result from the Extraction Contactor \#1 Drain Pipe}
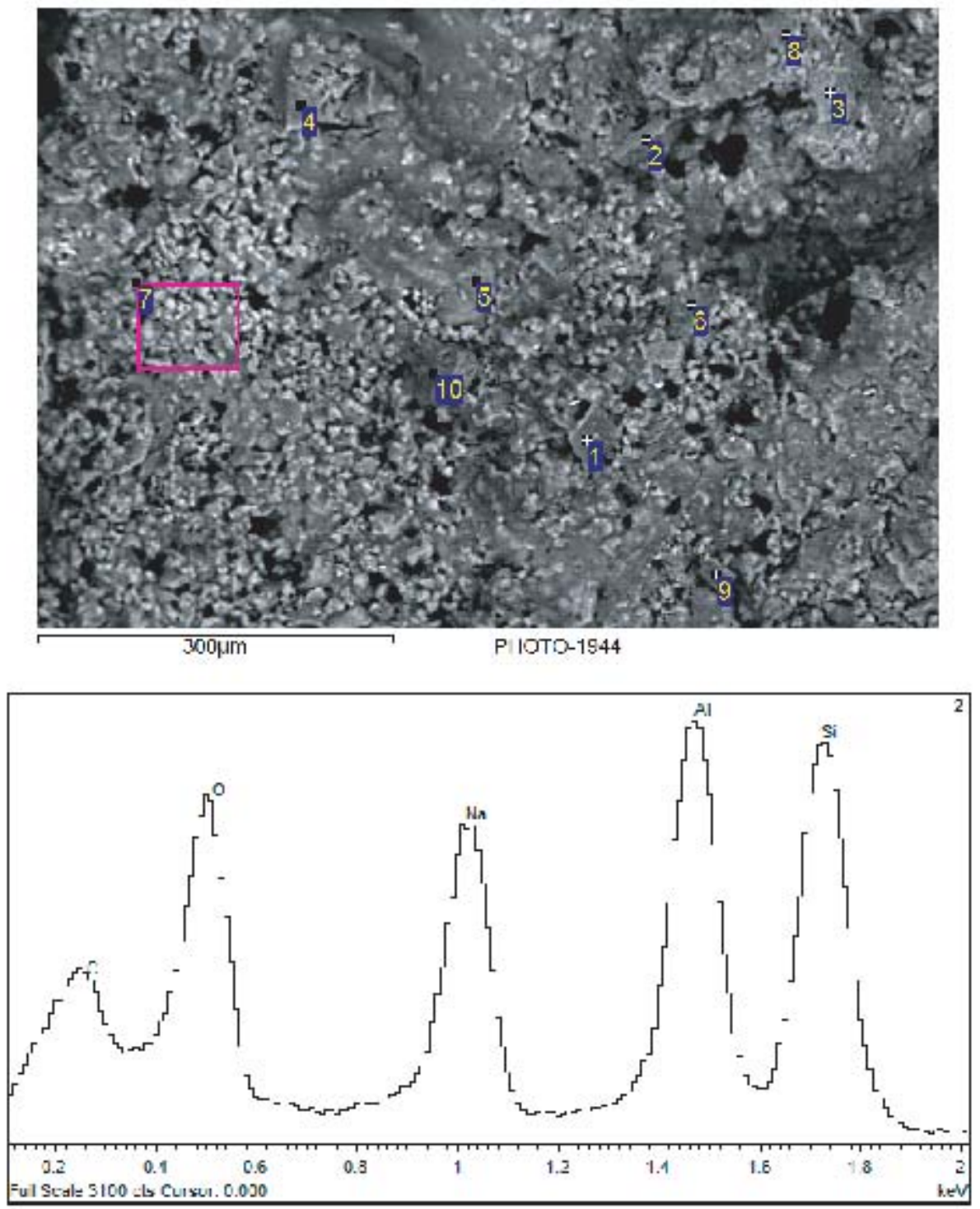

A wet sample of the solids was digested in aqua regia, and the digestate was forwarded for ICPES analysis. Table 9 shows the results for the sample. 
SRNL-STI-2014-00336

Revision 0

\section{Table 9. ICPES Results for the Digested Wet Solids from Drain Pipe Solids}

\begin{tabular}{|c|c|}
\hline Analyte & Result $(\boldsymbol{\mu g} / \mathbf{g})$ \\
\hline $\mathrm{Al}$ & 82100 \\
\hline $\mathrm{B}$ & 10.7 \\
\hline $\mathrm{Cr}$ & 37 \\
\hline $\mathrm{Fe}$ & 215 \\
\hline $\mathrm{K}$ & 342 \\
\hline $\mathrm{Na}$ & 95400 \\
\hline $\mathrm{P}$ & $<9.08$ \\
\hline $\mathrm{S}$ & $<399$ \\
\hline $\mathrm{Si}$ & 721 \\
\hline $\mathrm{Ti}$ & 375 \\
\hline $\mathrm{Zn}$ & 3.7 \\
\hline
\end{tabular}

The analytical uncertainty for the ICPES analysis is $10 \%$.

The high aluminum result is due to the presence of the aluminosilicate, and this is corroborated by the high sodium value. However, the silicon value is far lower than it should be if the aluminum is mostly from aluminosilicate. ${ }^{\Sigma}$ Past history has shown that sometimes the silicon is difficult to cleanly dissolve, so a second digestion was performed on a sample of the dried solids, this time using a sodium peroxide fusion method, which is known to completely dissolve silicon (however, this method cannot be used if a sodium result is needed). The digested material was sent for ICPES analysis (Table 9). At the same time a further solid sample was analyzed for wt\% total solids (Table 9).

With the sodium peroxide fusion digestion, the ICPES results provided the aluminum:silicon ratio that would be expected for the aluminosilicate compound. This confirms that the bulk of the solids are aluminosilicate. The relatively higher analyte results in the sodium peroxide fusion sample are most likely due to the fact that the values reported in Table 8 are on the wet or hydrated solids (results include water weight), as opposed to the results in the sodium peroxide fusion (Table 10) which were dried solids.

\footnotetext{
${ }^{\Sigma}$ The aluminosilicate materials identified in our CXRD have an Na:Al:Si molar ratio of 1.33:1:1. Given that these elements have similar atomic weights (23:27:28), one would expect the elemental concentrations from digested aluminosilicate compounds to be similar.
} 
Table 10. Second Sample Results for the Dry Digested Solids from Drain Pipe Solids

\begin{tabular}{|c|c|}
\hline Analyte & Result $(\boldsymbol{\mu g} / \mathbf{g})$ \\
\hline $\mathrm{Al}$ & 140000 \\
\hline $\mathrm{B}$ & $<81.7$ \\
\hline $\mathrm{Cr}$ & $<263$ \\
\hline $\mathrm{Fe}$ & 578 \\
\hline $\mathrm{K}$ & $<7650$ \\
\hline $\mathrm{Na}$ & $\mathrm{NA}$ \\
\hline $\mathrm{P}$ & $<3540$ \\
\hline $\mathrm{S}$ & $<200000$ \\
\hline $\mathrm{Si}$ & 136000 \\
\hline $\mathrm{Ti}$ & 825 \\
\hline $\mathrm{Zn}$ & $<77.8$ \\
\hline Total wt\% solids & $68.0 \%$ \\
\hline
\end{tabular}

The analytical uncertainty for the analyses is $10 \%$.

A sample of the drain pipe solids was dissolved in water with stirring overnight. While the majority of the solids dissolved, the solution was cloudy which indicates some insoluble material was present. Therefore, the subsequent IC-Anions analysis may not accurately reflect the total solids composition. See Table 11 for the IC-Anions results.

Table 11. IC-Anions Results for the Dissolved Drain Pipe Solids

\begin{tabular}{|c|c|}
\hline Analyte & Result $(\boldsymbol{\mu g} / \mathbf{g})$ \\
\hline $\mathrm{F}$ & $<408$ \\
\hline Formate & $<408$ \\
\hline $\mathrm{Cl}$ & $<408$ \\
\hline Nitrite & 979 \\
\hline $\mathrm{Br}$ & $<408$ \\
\hline Nitrate & 80800 \\
\hline Phosphate & $<408$ \\
\hline Sulfate & 490 \\
\hline oxalate & 19000 \\
\hline
\end{tabular}

The analytical uncertainty for all the analysis is $10 \%$. 
The high nitrate result corroborates the presence of sodium nitrate from the CXRD. The oxalate result is surprising given the lack of signal from the CXRD, but several of the peaks in the CSEM seem to indicate oxalate. This may have some relationship with the nitric acid cleaning that occurred in the contactors, as part of the attempts to restart MCU. Compared to the aluminum and silicon concentrations, the oxalate is relatively small. Refer back to section 2.0 for a discussion on the fabrication of the drain pipe sampler. Portions from each depth ( 3”, 6”, q”) were sent for CXRD and CSEM analyses. All of the CXRD results showed only aluminosilicate.

CSEM results for all the samples showed similar identifications. Most of the points register only aluminum, silicon (aluminosilicate), sodium, carbon and oxygen (possibly oxalate). There are some spots registering $\mathrm{Ti}$, and a few spots registering iron, chromium and nickel (stainless steel). There are a few spots that register either mercury or tin, similar to earlier samples.

Together, the CXRD and CSEM are strong indications that the contents of the pipe, at least to the depths we sampled, are approximately the same bulk composition.

Of the solids, the approximate wt\% breakdown of the wet solids mass is given in Table 12 .

Table 12. Approximate Mass Breakdown of Wet Solids from the Extraction Contactor

\begin{tabular}{|c|c|}
\hline Compound & wt\% of wet solids \\
\hline water & $32 \%$ \\
\hline Sodium aluminosilicate & $56.2 \%$ \\
\hline Sodium oxalate & $2.9 \%$ \\
\hline Sodium nitrate & $11.1 \%$ \\
\hline
\end{tabular}


Figure 12. Pipe Solids Removal Tool

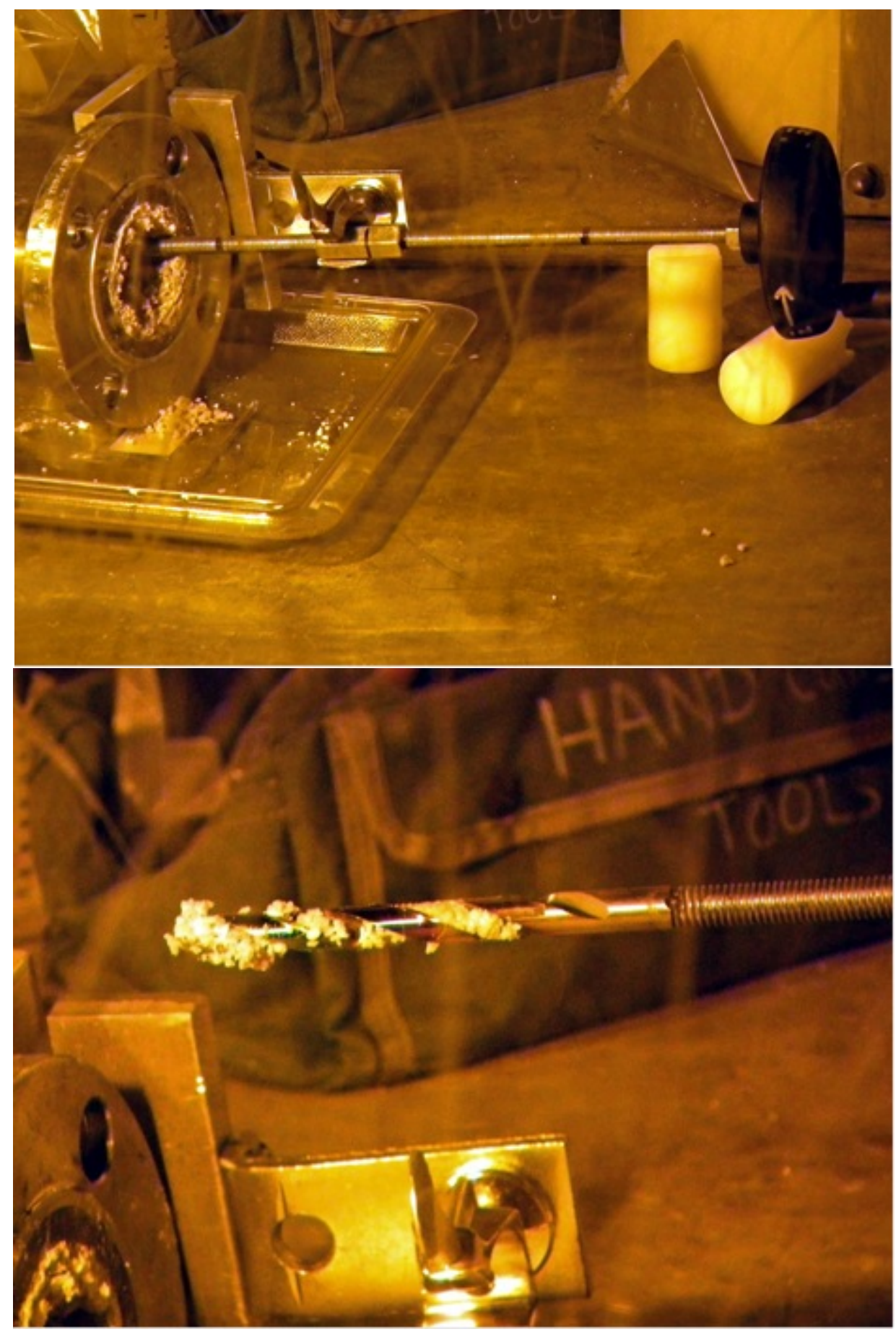




\subsubsection{Tank 49H Variable Depth Samples}

The discovery of oxalate solids in MCU caused SRNL to examine whether or not the feed material that goes to MCU was responsible. During previous MCU-related work, SRNL thoroughly analyzed several variable depth samples of the Tank 49H feed material (HTF-E-165, -166, -167, -168, -169). ${ }^{8}$ In May 2014, the three solutions were examined again and noted the same faint haziness (Figure 13).

\section{Figure 13. Tank 49H Samples 8 Months after Receipt}

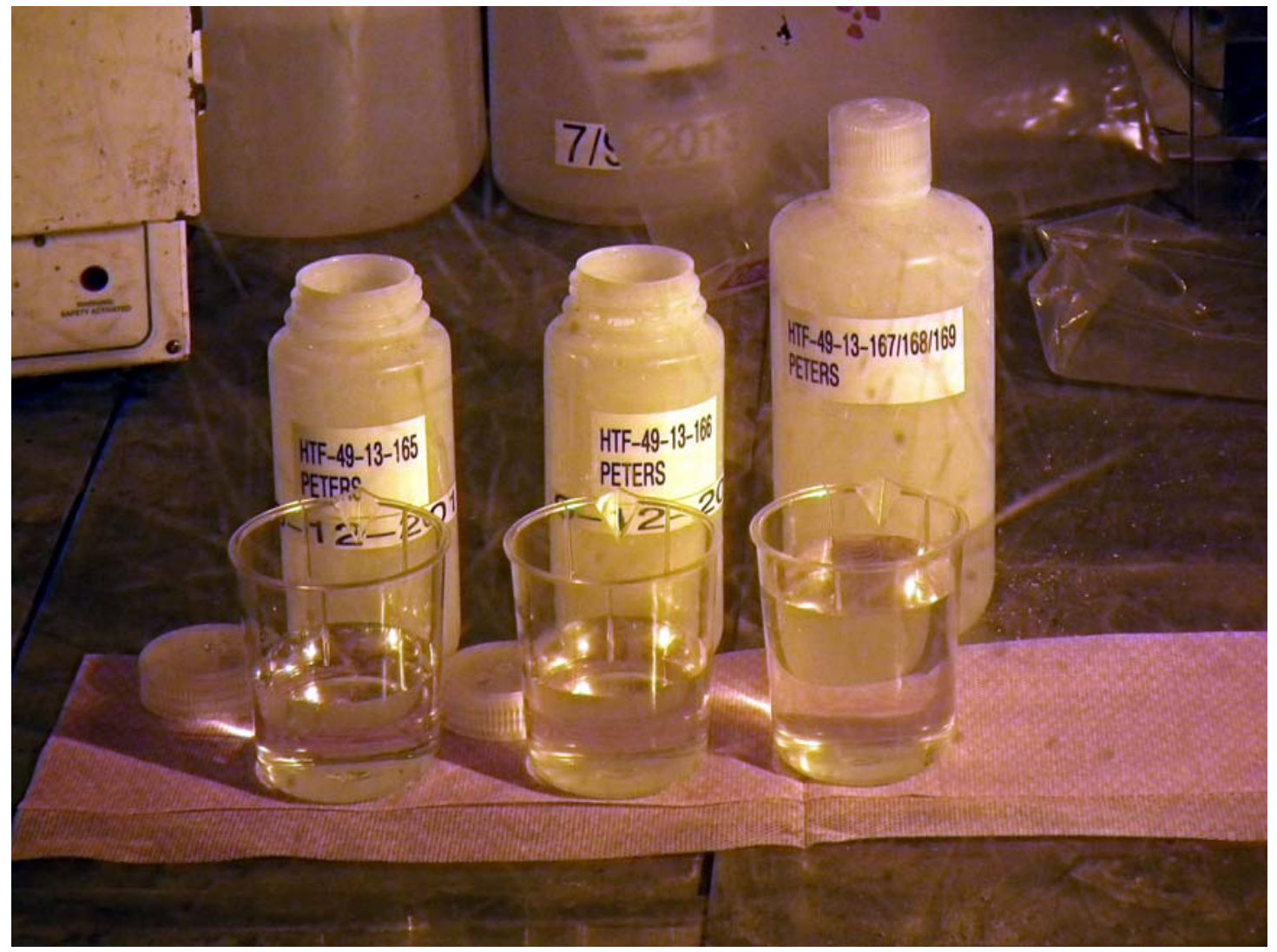

It was decided to isolate and analyze the solids. The HTF-F-167/168/169 solution composite was filtered through a removable $0.45 \mu \mathrm{m}$ filter disk and the filter disk sent to CXRD (Figure 14). 
Figure 14. CXRD Result from HTF-E-167/168/169 Tank 49H Composite

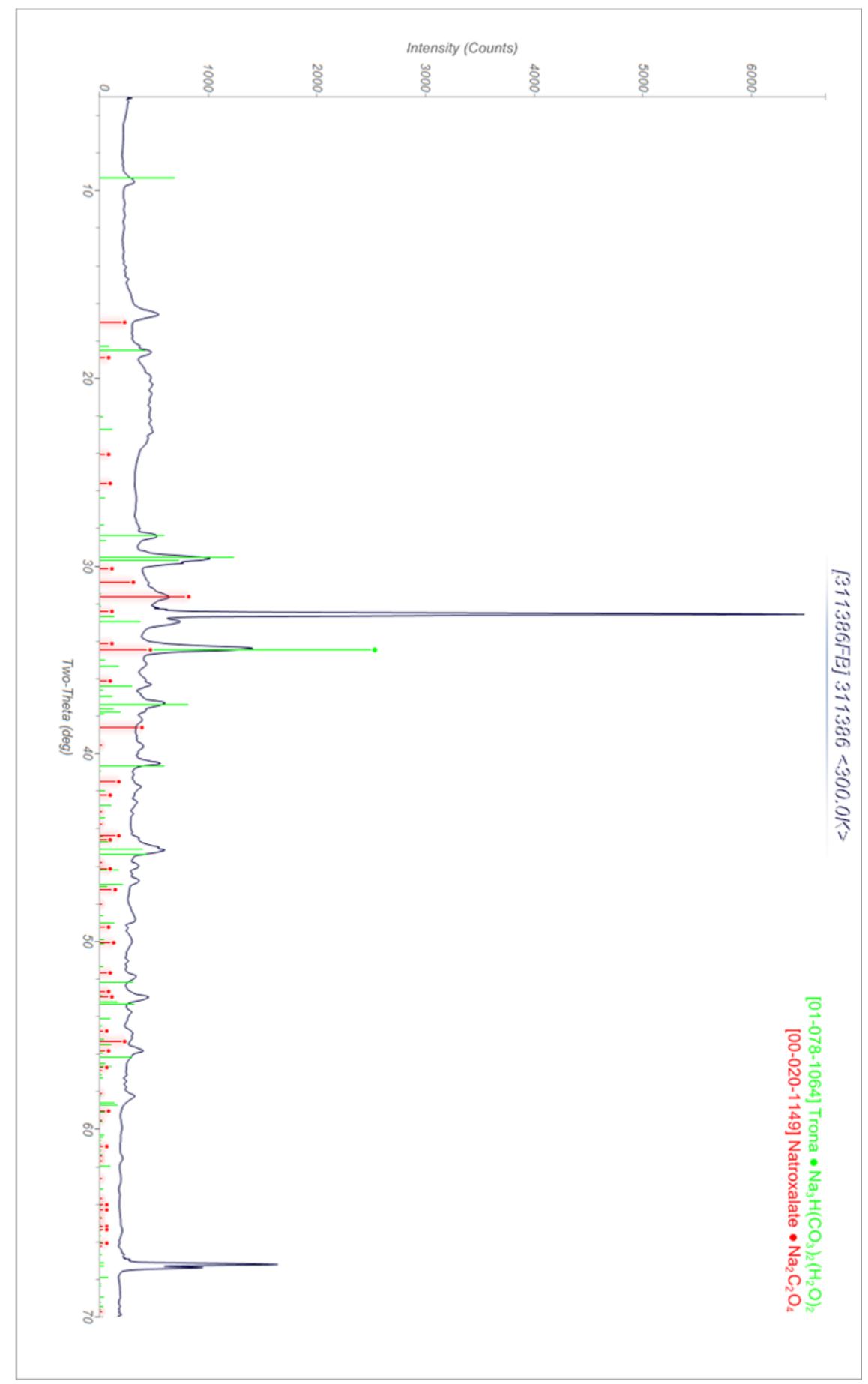


Two compounds were noted, trona $\left(\mathrm{Na}_{3} \mathrm{H}\left(\mathrm{CO}_{3}\right)_{2} \cdot 2 \mathrm{H}_{2} \mathrm{O}\right)$ and sodium oxalate. This is the first observation of trona, and this compound might be due to the extended absorption of atmospheric $\mathrm{CO}_{2}$ onto residual caustic solution in the filter media (this phenomena has been previously noted $)^{8}$. The sodium oxalate is not surprising given the results from other samples.

After the CXRD, the sample was sent for CSEM analysis (Figure 15).

Figure 15. Typical CSEM Result from HTF-E-167/168/169 Tank 49H Composite
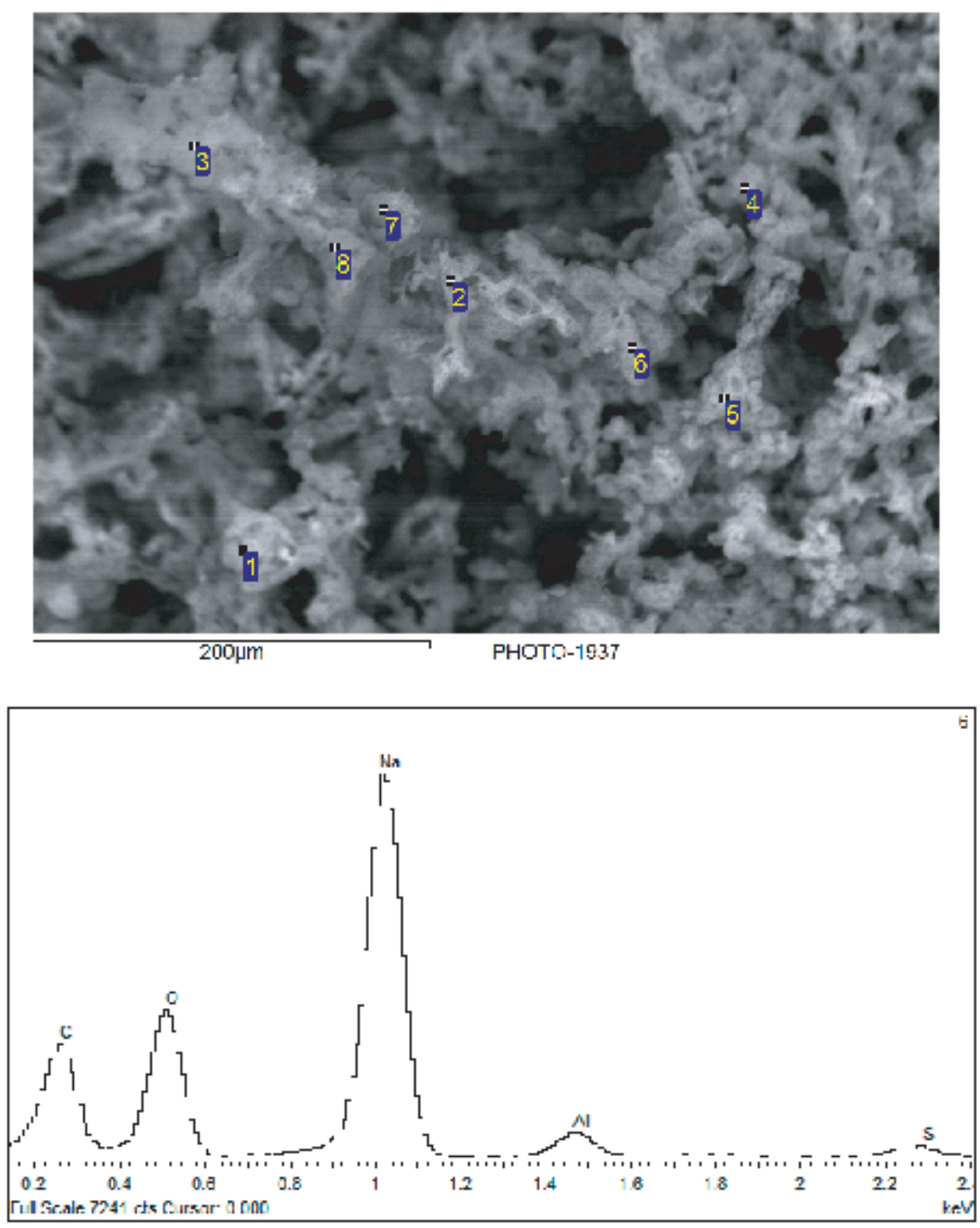

The solids in this sample do not have the same general appearance as the other oxalate samples; this may be due to a finer grain of solids in this sample. 
Most of the points register only sodium, carbon and oxygen (probably oxalate or carbonate), with some peaks from aluminum and silicon (aluminosilicate). There are some spots registering iron, chromium and nickel (stainless steel). There are a few spots that register mercury, for reasons unknown at this time.

\subsubsection{Solids from the SSFT}

The initial inspection of the MCU Salt Solution Feed Tank (SSFT) indicated a large quantity of precipitated solids were present. Samples of the solids were removed and sent to SRNL for analysis (Figure 16). While results from the SSFT solids have been previously reported, some are repeated here for continuity. ${ }^{9}$

Figure 16. Solids from the SSFT

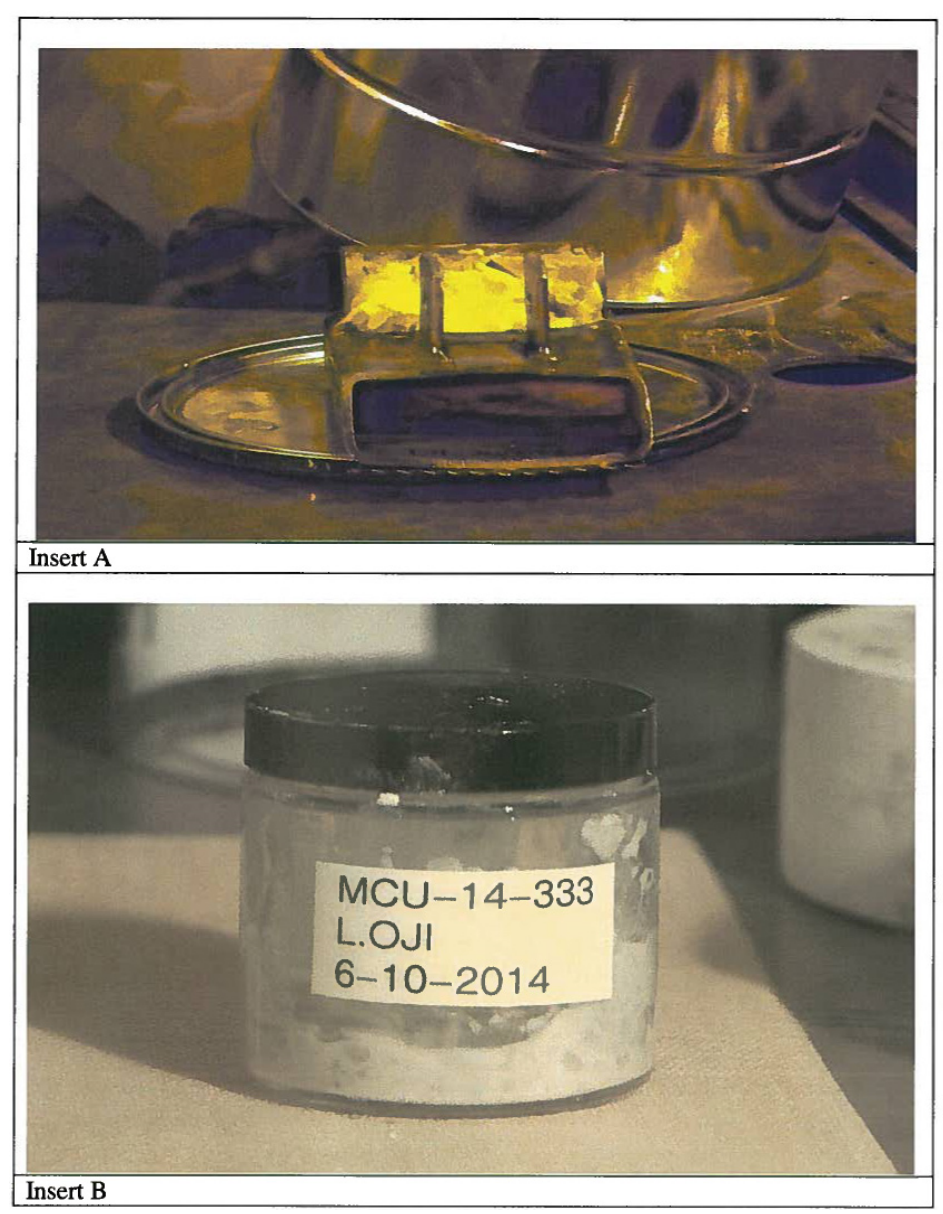

The SSFT CXRD (Figure 17) sample shows both oxalate and aluminosilicate as bulk constituents. A sample of the solids sent to CSEM is illustrated in Figure 18. 
SRNL-STI-2014-00336

Revision 0

Figure 17. CXRD Result from SSFT Solids

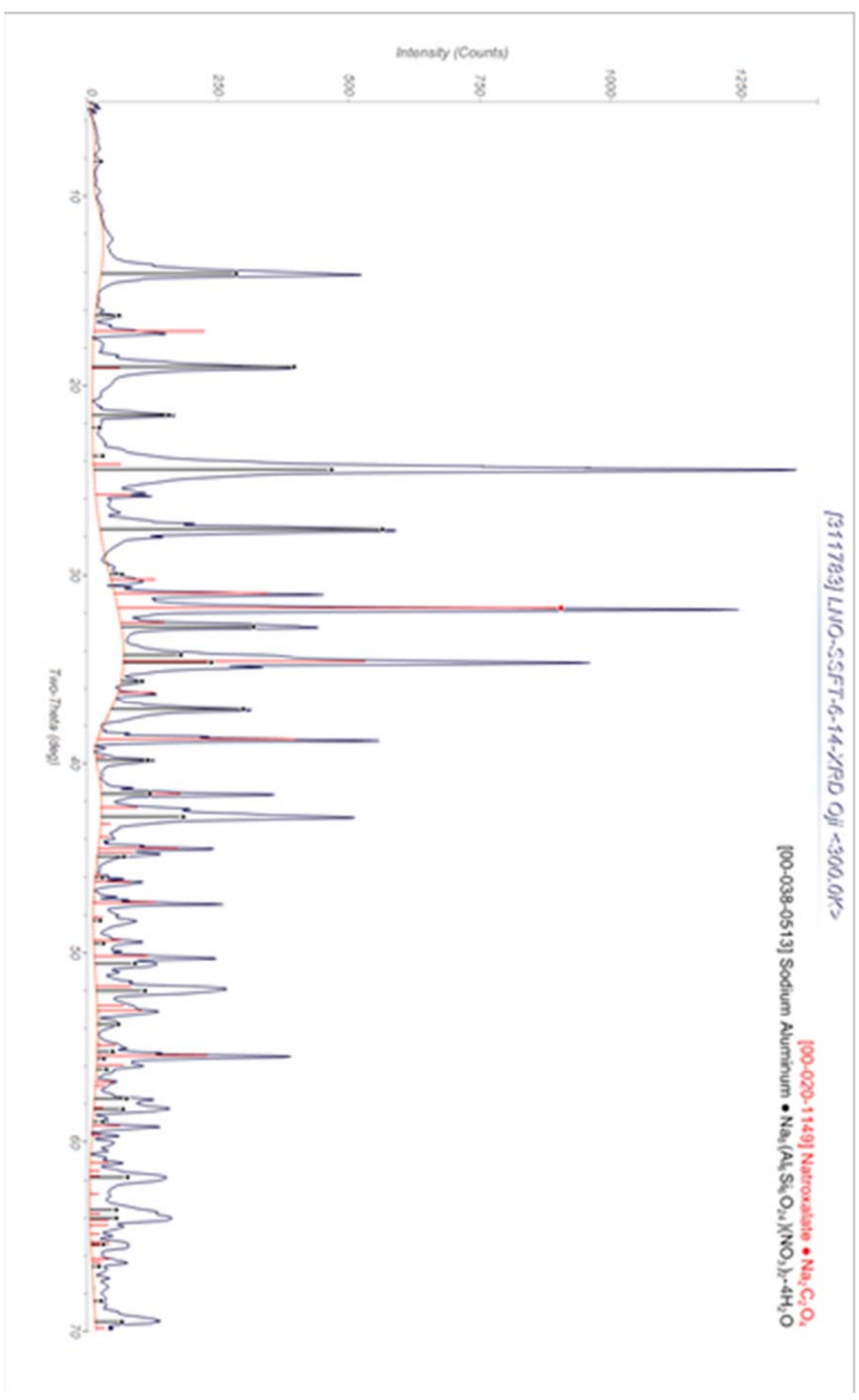


Figure 18.Typical CSEM Result of the SSFT Solids

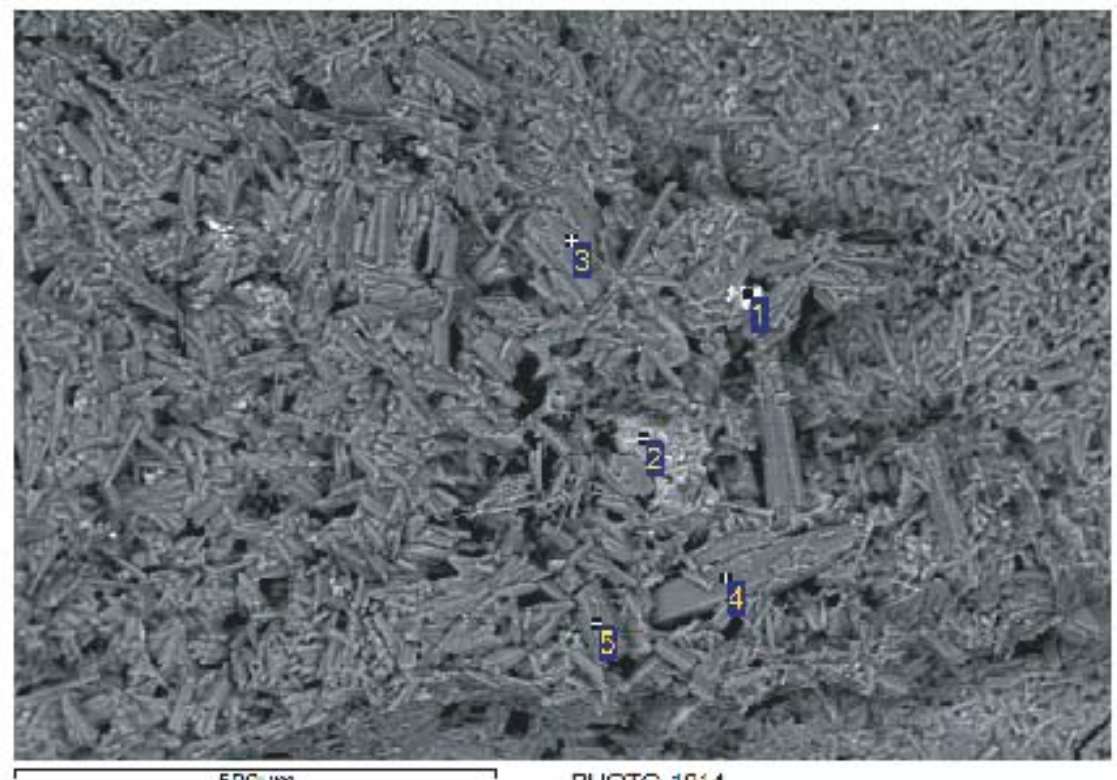

$500 \mathrm{um} \quad$ PIIOTO-1914

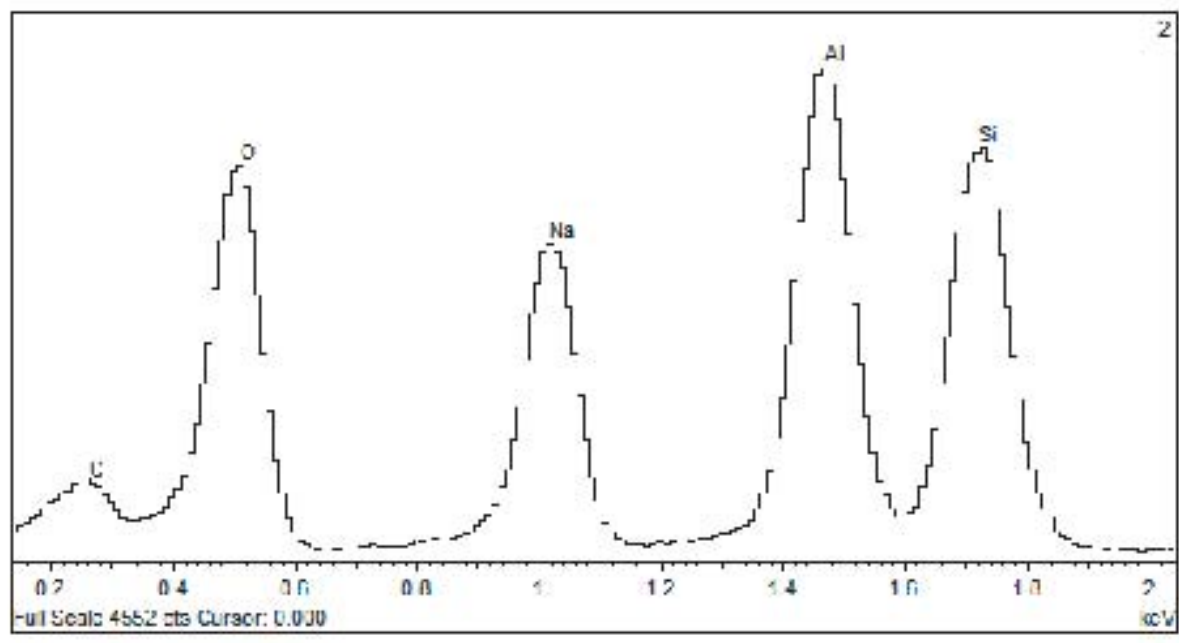

Figure 18 shows that the CSEM peaks are typically sodium, carbon and oxygen (probably oxalate), with some peaks from aluminum and silicon (aluminosilicate). There were a few peaks with titanium and uranium (possibly MST solids). Note the needle like shapes seen in the extraction and scrub contactor solids. 
Sample of the SSFT solids were digested by both aqua regia and a sodium peroxide fusion, and the resulting solutions sent for ICPES analysis (Table 13). The aqua regia is a wet solids measurement while the sodium peroxide is a dry solid measurement, so direct comparison between the two methods must consider the wt\% solids result in the sodium fusion sample. Radiological results (gamma scan and scintillation) are previously reported. ${ }^{9}$

Table 13. ICPES Results from Digested SSFT Solids

\begin{tabular}{|c|c|c|}
\hline \multirow{2}{*}{ Analyte } & \multicolumn{2}{|c|}{ Result $(\boldsymbol{\mu g} / \mathbf{g})$} \\
\cline { 2 - 3 } & Aqua Regia & Sodium Peroxide \\
\hline $\mathrm{Al}$ & 70800 & 96300 \\
\hline $\mathrm{B}$ & 19.6 & $<80.8$ \\
\hline $\mathrm{Cr}$ & 41.2 & $<260$ \\
\hline $\mathrm{Fe}$ & 210 & 744 \\
\hline $\mathrm{K}$ & 211 & $<7560$ \\
\hline $\mathrm{Na}$ & 184000 & $\mathrm{NA}$ \\
\hline $\mathrm{P}$ & $<28.4$ & $<3500$ \\
\hline $\mathrm{S}$ & 1250 & $<200000$ \\
\hline $\mathrm{Si}$ & 548 & 90500 \\
\hline $\mathrm{Ti}$ & 943 & 1200 \\
\hline $\mathrm{Zn}$ & 6.65 & $<76.9$ \\
\hline $\mathrm{Wt} \% \mathrm{solids}$ & $\mathrm{NA}$ & $76.2 \%$ \\
\hline
\end{tabular}

The analytical uncertainty for the ICPES analysis is $10 \%$.

Even with the wet vs. dry solids differences, we can say that the silicon is not being permanently dissolved by the aqua regia, which was already established in the course of this work.

A sample of the SSFT solids was dissolved in water with stirring overnight. While the majority of the solids dissolved, the solution was faintly cloudy which indicates some insoluble material was present. Therefore, the subsequent IC-Anions analysis may not accurately reflect the total solids composition. Two samples of the solids were also dissolved in dilute (0.5 M) nitric acid, which did provide for complete solids dissolution. See Table 14 for the IC-Anions results. Values in parentheses for the nitric acid results are \%RSD from the average of two results.

Given the similarity in the oxalate results, it appears that either method dissolves all the oxalate salts, and that once again, oxalate represents a large portion of the solids. 
Table 14. IC-Anions Results for the Dissolved SSFT Solids

\begin{tabular}{|c|c|c|}
\hline \multirow{2}{*}{ Analyte } & Nitric acid & Water \\
\cline { 2 - 3 } & Result $(\boldsymbol{\mu} \mathbf{g} / \mathbf{g})$ & Result $(\boldsymbol{\mu g} / \mathbf{g})$ \\
\hline $\mathrm{F}$ & $<333$ & $<500$ \\
\hline Formate & $<333$ & $<500$ \\
\hline $\mathrm{Cl}$ & $<333$ & $<500$ \\
\hline Nitrite & $<333$ & 6140 \\
\hline $\mathrm{Br}$ & $1670(0.00 \%)$ & $<2500$ \\
\hline Nitrate & $\mathrm{NA}$ & 50600 \\
\hline Phosphate & $<333$ & $<500$ \\
\hline Sulfate & $4265(18.1 \%)$ & 1590 \\
\hline oxalate & $151000(14.1 \%)$ & 157000 \\
\hline
\end{tabular}

The analytical uncertainty for the analyses is $10 \%$.

\subsubsection{Solution from the SSFT}

A sample of the solution from the SSFT was removed and sent to SRNL for analysis. While results from the SSFT solution have been largely been previously reported, we now report the IC-Anions results (Table 15). ${ }^{9}$ Values from a set of four averaged samples from the DSSHT are present as a point of comparison. These were MCU-14-337, -338, -352, and -354 (all of these samples were taken shortly before the sampling of the SSFT on 6/10/14). The DSSHT values are averages with the values in parentheses as \% relative standard deviation (RSD).

Table 15. IC-Anions Results for the SSFT Solution

\begin{tabular}{|c|c|c|c|}
\hline \multirow{2}{*}{ Analyte } & \multicolumn{3}{|c|}{ Result $(\boldsymbol{\mu g} / \mathbf{g})$} \\
\cline { 2 - 4 } & SSFT & Tank 49H & DSSHT \\
\hline $\mathrm{F}$ & $<100$ & NA & $<10$ \\
\hline Formate & 381 & 354 & $267(20.1 \%)$ \\
\hline $\mathrm{Cl}$ & 167 & 109 & $144(13.1 \%)$ \\
\hline Nitrite & 21200 & 26900 & $21600(16.4 \%)$ \\
\hline $\mathrm{Br}$ & $<500$ & NA & $<500$ \\
\hline Nitrate & 126000 & 166000 & $151000(9.25 \%)$ \\
\hline Phosphate & 359 & 424 & $395(11.8 \%)$ \\
\hline Sulfate & 5900 & 6830 & $6043(16.7 \%)$ \\
\hline oxalate & 858 & 260 & $288(19.3 \%)$ \\
\hline
\end{tabular}

The analytical uncertainty for the analyses is $10 \%$. 
Across the different samples, most of the analytes are statistically indistinct from each other, indicating only the expected system dilution that occurs from the SSFT to the DSSHT. The one exception is the oxalate value. As a point of comparison, the last analysis of the Tank $49 \mathrm{H}$ feed (variable depth samples) gave an oxalate concentration of $260 \mathrm{mg} / \mathrm{L},{ }^{8}$ and the last analysis of the late wash hold tank (LWHT) gave $103 \mathrm{mg} / \mathrm{L}^{8}$

The oxalate increase in SSFT as compared to the feed solution implies some sort of oxalate accumulation between the feed and the SSFT, followed by uptake of oxalate in solution, which can then carry forward. Given that on May 28, 29 and June 3 solutions from the SSFT were carried directly forward to the DSSHT, this would affect the DSSHT values at that time.

\subsubsection{Transfer of CDT Material to the SEHT}

On April 7, a SEHT sample delivered to F/H Lab (MCU-14-226) was measured to have a pH value of 12.24, which was far higher than the previously typical 7.5 to 8.5 . As confirmation, two samples from the SEHT (MCU-14-233/236) were sent to SRNL for analysis. This sample had a measured $\mathrm{pH}$ of 12.31, which is well above the DWPF waste acceptance limit of 11.

F/H Lab received a SEHT sample, MCU-14-267 on April 23. The technicians there reported the sample being faintly cloudy which is typically a result of the presence of fine solids. This particular sample was taken before the transfer of material from the CDT to the SEHT.

In order to put the material in the SEHT within the $\mathrm{pH}$ specification, it was decided to transfer some of the material from the Contactor Drain Tank (CDT) to the SEHT. The material in the CDT is acidic, and its transfer would help drive the $\mathrm{pH}$ in the SEHT towards the acceptable limits. On April 24, 186 gallons of the CDT was transferred to the SEHT which had a volume of 689 gallons before the CDT transfer.

On April 24, F/H received the SEHT sample set of MCU-14-268/269/270 (post CDT transfer). MCU-14-268 which had a measured $\mathrm{pH}$ of 8.23, indicating that the CDT material transfer successfully dropped the $\mathrm{pH}$. However, this sample had plainly visible solids (Figure 19). 


\section{Figure 19. Solids Noted in SEHT Sample MCU-14-268}

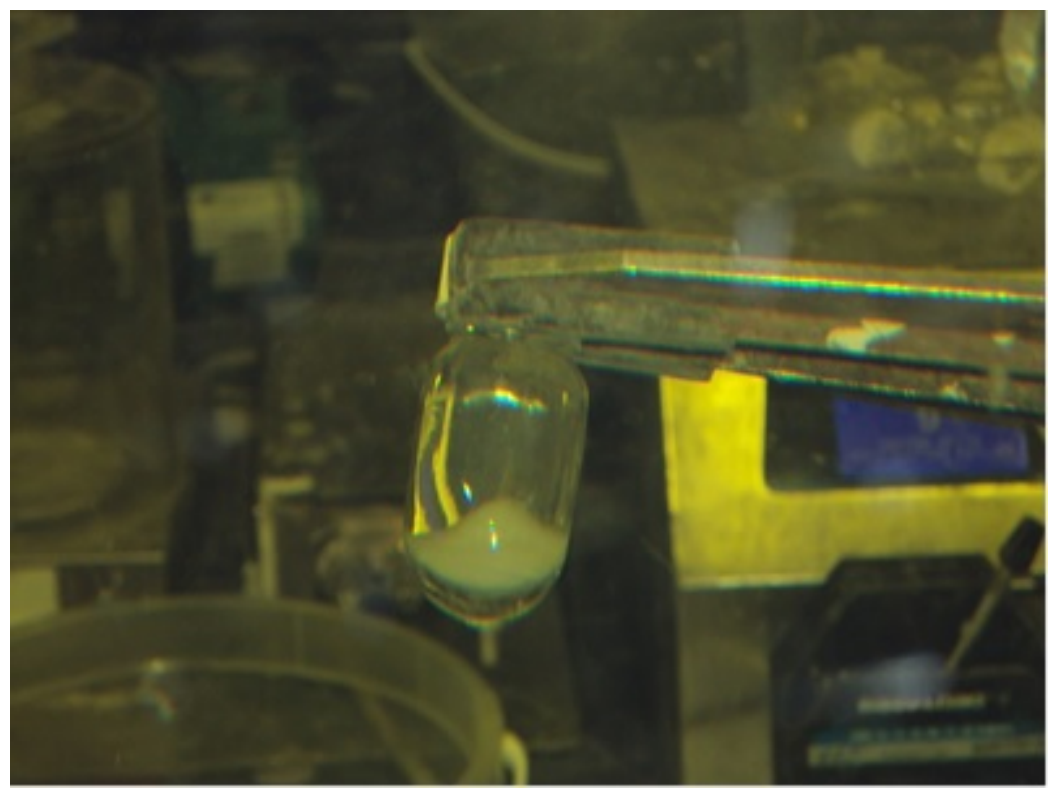

MCU-14-269 was then examined. Faint cloudiness was noted in this sample, similar to that seen in MCU-14-267, but not like the obvious solids in MCU-14-268. Finally, MCU-14-270 was examined. As with MCU-14-268, obvious solids were noted (very similar to those seen in Figure 19). All three of the immediate post-CDT transfer samples shows one degree or another of solids.

On Friday, April 25, SRNL confirmed the visual observations made by F/H Lab on all four samples. It appeared that the transfer of material from the CDT to the SEHT had precipitated solids.

On April 28, a sample (MCU-14-278) from the SEHT was sent to SRNL for solids analysis. Upon receipt, the sample was observed to have no obvious solids. The sample was filtered through a removable filter element. The material filtered very quickly, leaving no visible solids. The filter element was then sent to AD for CXRD analysis. However, no signal could be detected, other than for the filter element itself.

On April 29, the MCU-14-270 sample was sent to SRNL to attempt to isolate the solids. Upon its arrival, the researchers noted that the sample vial was faintly cloudy, but there were no bulk solids present. The sample was filtered through a nylon filter cup to capture any solids. The material filtered very quickly, leaving no visible solids. The filter cup was sent in its entirety for CXRD analysis. The filter element was removed an analyzed, however, no signal could be discerned, other than for the filter element itself. Whatever solids were present were in very low concentration. 
The transfer of material from the CDT to the SEHT on April 24 was intended to lower the $\mathrm{pH}$ of the SEHT. While this was successful, it had the byproduct of creating solids, at least for a short period, which was not unanticipated. ${ }^{10}$ The observed white solids were more than likely small amounts of aluminum hydroxide, which is known to precipitate below $\mathrm{pH}$ of $\sim 10$, in fine, gelatinous solids. Efforts to capture these solids were not successful, and further SEHT samples have shown no further solids.

\subsection{Summary of Oxalate Data}

Given the discovery of sodium oxalate solids in many parts of MCU, an overview of historical oxalate results are relevant. SRNL has collected sample results from various Salt Batch blend documents, as well as the few analysis performed at SRNL.

It must be recognized that oxalate can come from two sources; oxalic acid is used in the ARP filter cleaning, and oxalate exists in the dissolved salt cake (feed material), and the amount has been dependent on the particular salt batch (Table 16).

Table 16. Oxalate Concentration in the Salt Batch Feeds

\begin{tabular}{|c|c|}
\hline Salt Batch & Oxalate Concentration (mg/L) \\
\hline 1 & $<526$ \\
\hline 2 & $<250$ \\
\hline 3 & 129 \\
\hline 4 & 200 \\
\hline $4 \mathrm{a}$ & 145 \\
\hline 5 & 238 \\
\hline $6 \mathrm{a}$ & 278 \\
\hline $6 \mathrm{~b}$ & 290 \\
\hline $6 \mathrm{c}$ & 297 \\
\hline $6 \mathrm{~d}$ & 304 \\
\hline 7 & 357 \\
\hline
\end{tabular}

The analytical uncertainty for the analyses are $10 \%$.

Over time, the oxalate concentration in the feed materials has been increasing. At the same time, there was an overall increase in sodium concentration from the addition of $\mathrm{NaOH}$ to prevent aluminosilicate precipitation (although salt batch 7 was $\sim 5 \%$ lower in sodium than salt batch 6). Addition of the sodium in the $\mathrm{NaOH}$ in turn decreases the oxalate solubility.

There are a limited number of oxalate analyses in the recent DSSHT and SEHT samples, which are listed in Table 17. Historically, oxalate has not been a measurement of concern; this is why there are so few measurements of this. The Preliminary, Microbatch 5, and Microbatch 6a 
samples were taken during the changeover to the NGS blend solvent. The Preliminary sample suffered from an unmeasured system dilution (from cold chemical heels and cleaning), and thus should be considered a lower bound value. Otherwise, the Microbatch samples indicate no significant change between the input and output - apparently no precipitation or uptake of oxalate is occurring during that time.

After the restart of routine operations, the monthly samples we have indicated that there were no disruptions in the oxalate concentrations until sometime in April 2014, after the samples from April 9.

Table 17. Oxalate Concentration is the DS or SE Samples

\begin{tabular}{|c|c|c|}
\hline Salt Batch & Date & $\begin{array}{c}\text { Oxalate } \\
\text { Concentration (mg/L) }\end{array}$ \\
\hline NGS changeover & & 227 \\
\hline Preliminary (DSSHT) & $12 / 6 / 2013$ & 340 \\
\hline Microbatch 5 (DSSHT) & $1 / 8 / 2014$ & 337 \\
\hline Microbatch 6a (DSSHT) & $1 / 18 / 2014$ & \\
\hline CDT to SEHT transfer & $4 / 24 / 2014$ & $<50$ \\
\hline Monthly & & 990 \\
\hline MCU-14-233/236 (SEHT) & $4 / 9 / 2014$ & 321 \\
\hline MCU-14-283 (SEHT) & $4 / 26 / 2014$ & 177 \\
\hline MCU-14-290 (DSSHT) & $4 / 28 / 2014$ & \\
\hline MCU-14-313/314 (DSSHT) & $5 / 16 / 2014$ & \\
\hline
\end{tabular}

The analytical uncertainty for the analyses are $10 \%$.

On April 9, SRNL received two SEHT samples, MCU-14-233 and -236. These samples were from the SEHT before the transfer of CDT material. The two samples were composited and mixed. This composite was analyzed to have a less than detectable concentration of oxalate. Material from the CDT was transferred to the SEHT on April 24.

On April 28, SRNL received a set of six (post CDT transfer) SEHT p-nut vials; MCU-14-278, 279, -283, -284, -288, -289. Sample MCU-14-283 was analyzed for oxalate content, which measured $990 \mathrm{mg} / \mathrm{L}$. The contents of the CDT before transfer were previously analyzed to have an oxalate concentration of $6280 \mathrm{mg} / \mathrm{L} .^{7} 186$ gallons of CDT material @6280 mg/L was transferred into 689 gallons of SEHT @ $0 \mathrm{mg} / \mathrm{L}(<50 \mathrm{mg} / \mathrm{L}$, treat as 0$)$. This should then drive the post transfer SEHT oxalate concentration to $1335 \mathrm{mg} / \mathrm{L}$. The difference between the theoretical oxalate concentration $(1335 \mathrm{mg} / \mathrm{L})$ and the measured $(990 \mathrm{mg} / \mathrm{L})$ is likely to be due to precipitation of oxalate. However, given the single data point for each sample and the possible heterogeneous nature of the CDT, the difference between the measured and predicted values may not be statistically significant. 
The CDT to SEHT transfer did not affect the DSSHT oxalate values; the April 28 DSSHT sample (MCU-14-290) gave the expected oxalate concentrations. However, the next monthly DSSHT sample (MCU-14-313/314) showed a marked decline in oxalate concentration (177 $\mathrm{mg} / \mathrm{L}$ ). The reasons for the decline were unknown at the time. By June, after the inspection of the SSFT (see section 3.2.5), there was the realization that oxalate was being likely being carried forward through the system.

Given the varied results from different points at ARP and MCU, a careful consideration must be given to the system as a whole (Figure 20). ${ }^{11}$

\section{Figure 20. ARP Process Overview}

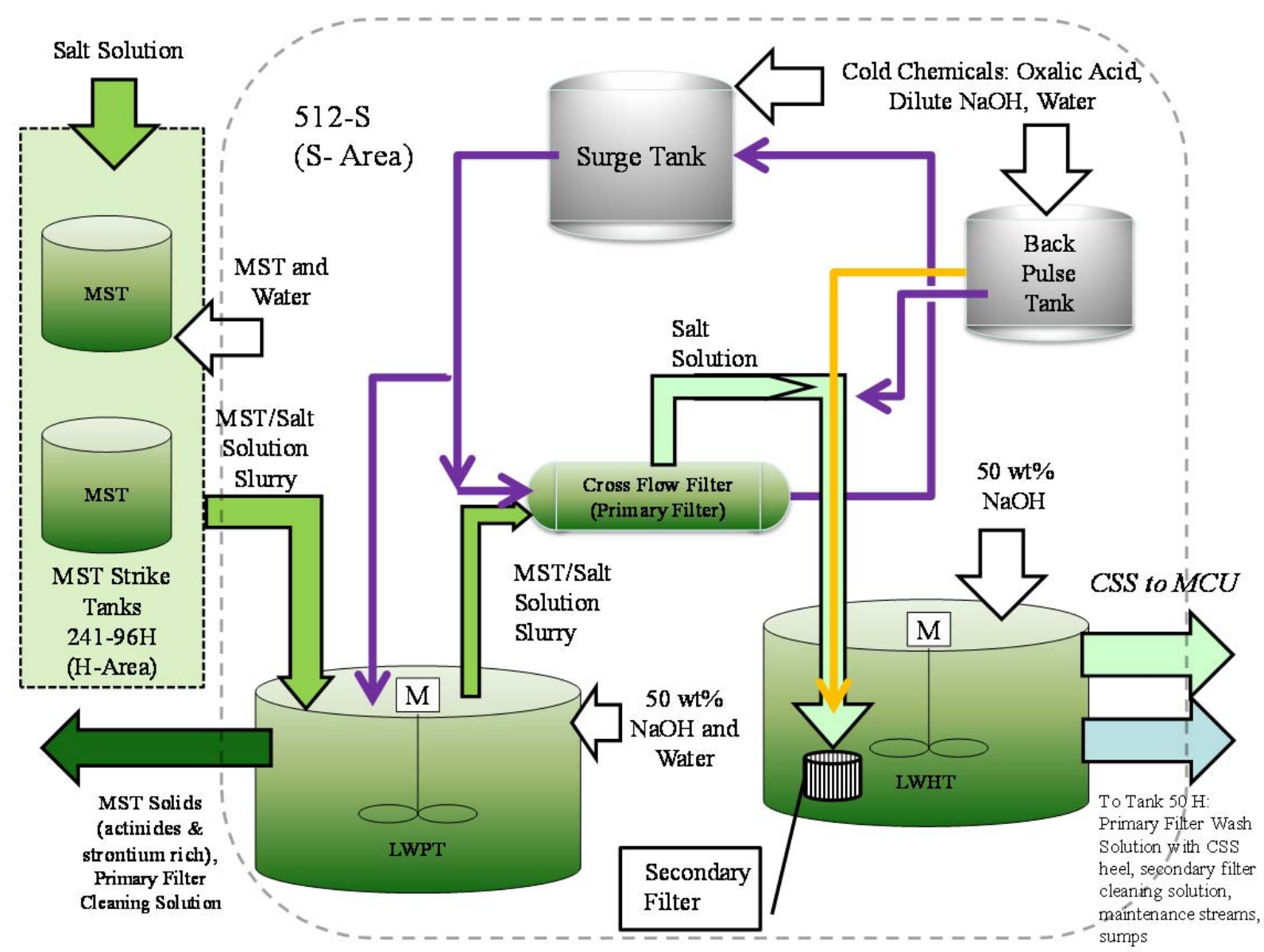

Given the tank 49 oxalate concentration, precipitation of oxalate solids is likely to be occurring in the LWPT or MST strike tanks - a recent analysis shows an oxalate concentration of 106 $\mathrm{mg} / \mathrm{L}$ (samples LWPT-1 and LWPT-2), ${ }^{8}$ while other analytes are approximately as the salt feed solution. Even if there was precipitation prior to the $512 \mathrm{~S}$ process, the agitation of the strike 
tanks is energetic enough to mobilize MST solids, and therefore is likely to mobilize oxalate solids.

The precipitated sodium oxalate in the LWPT likely accumulates over time, and doesn't get carried to the LWHT due to the primary and secondary filters. A sample from the LWHT taken at the same time as the previously mentioned LWPT samples shows an oxalate value of approximately the same $(103 \mathrm{mg} / \mathrm{L}-\mathrm{LWHT}-1) .{ }^{8}$ During MST washing operations, the precipitated sodium oxalate in the LWPT can become solubilized and carried to the LWHT. However, after the water washing, a slug of $50 \mathrm{wt} \% \mathrm{NaOH}$ follows (to clean out any aluminum compounds) into the LWHT. This cleaning solution still solubilizes a high amount of oxalate (3020 mg/L - sample LWPT-3) and this material goes into the LWHT. While most of the volume of the LWHT is removed from the system and transferred to Tank $50 \mathrm{H}$, there is still a residual heel of relatively concentrated oxalate. It is this heel that is thought to initiate precipitation of oxalate once mixed with filtered material transferred from the LWPT during normal operations. These solids can migrate to the SSFT, and once inside the SSFT, the solids can be distributed to the MCU contactors.

\subsection{Solids Recovery at MCU}

The various samples indicate a clear pattern of oxalate precipitation throughout the ARP and MCU systems. Solids precipitation is detrimental to the operation of the MCU system, and must be avoided. SRNL has previously considered ${ }^{12}$ several actions to mitigate the initial solids in the MCU system, and while it is beyond the scope to repeat them entirely, it is appropriate to highlight some of them.

- All solids should be removed from the tanks. While the aluminosilicate solids in the SSFT are likely legacy materials, it would be ideal to remove those to avoid potential later issues.

- Water is the best initial cleaning solution. This will be sufficient to dissolve oxalate materials.

- Agitation should be used to help dissolve any solids during cleaning attempts.

- Video inspection of the SSFT should be performed on a routine basis.

\subsection{Modeling of Sodium Oxalate Transport into MCU}

SRNL has attempted to model the transport of sodium oxalate from the SSRT to the MCU system. SRNL performed the analysis by reviewing available information on the properties of 
the solids and fluid that need to be transported and by reviewing the technical literature for information on transporting slurries through pipelines.

The following assumptions were made to perform the analysis:

- The particle density is $2.34 \mathrm{~g} / \mathrm{mL}$.

- The fluid density is $1.25 \mathrm{~g} / \mathrm{mL}$.

- The fluid viscosity is $3.0 \mathrm{cp}$.

- The particle concentration is $1 \%$.

- The pipe diameter is 1 inch.

- The particle size is $9 \mu$ and $48 \mu$. $^{\propto}$

- Flow rate is $3.5-8.5 \mathrm{gpm}(1.4-3.5 \mathrm{ft} / \mathrm{s}$ velocity)

\section{Vertical Pipelines}

One guideline for transporting solid particles in vertical pipelines is for the bulk fluid velocity to be greater than twice the particle settling velocity. ${ }^{13,14,15}$ To prevent solid particle transport, the bulk fluid velocity should be less than the settling velocity.

The particle settling velocity is calculated by the following equations ${ }^{16}$

$$
\begin{array}{ll}
\mathrm{v}_{\mathrm{s}}=g(\mathrm{~s}-1) \mathrm{d}_{\mathrm{p}}{ }^{2} / 18 v & \text { for } \mathrm{Re}_{\mathrm{p}}<1.4 \\
\mathrm{v}_{\mathrm{s}}=0.13[\mathrm{~g}(\mathrm{~s}-1)]^{0.72} \mathrm{~d}_{\mathrm{p}}^{1.18} v^{-0.45} & \text { for } 1.4<\operatorname{Re}_{\mathrm{p}}<500 \\
\mathrm{v}_{\mathrm{s}}=1.74\left[\mathrm{~g}(\mathrm{~s}-1) \mathrm{d}_{\mathrm{p}}\right]^{0.5} & \text { for } \operatorname{Re}_{\mathrm{p}}>500 \\
\operatorname{Re}_{\mathrm{p}}=\mathrm{d}_{\mathrm{p}} \mathrm{v}_{\mathrm{s}} / v &
\end{array}
$$

where $\mathrm{v}_{\mathrm{s}}$ is the settling velocity, $\mathrm{g}$ is the acceleration due to gravity, $\mathrm{s}$ is the ratio of particle and fluid densities ( $\mathrm{s}=$ particle density/fluid density), $\mathrm{d}_{\mathrm{p}}$ is the particle diameter, and $v$ is the fluid kinematic viscosity $(v=\mu / \rho)$.

To perform the calculation, one assumes a particle Reynolds number, calculates the settling velocity with the appropriate equation, and calculates a new particle the Reynolds number with the calculated settling velocity. If the Reynolds number is in the correct range for the equation used, the calculated settling velocity is correct. If the Reynolds number is not in the correct range for the equation used, use a different equation to calculate the settling velocity. Repeat these steps as necessary.

\footnotetext{
${ }^{\propto}$ The 9 and $48 \mu$ sizes were derived by examining a SEM image of the sodium oxalate material and measuring the height and width of 3 random crystals, and taking the averages of the height $(48 \mu)$ and width $(9 \mu)$.
} 
Table 18 shows the calculated settling velocity as well as the recommended transport velocity in vertical pipelines. The settling velocity and the required vertical transport velocity are much smaller than the axial velocity, so the sodium oxalate particles could be transported in a vertical transfer line.

Table 18. Recommended Vertical Transport Velocity

\begin{tabular}{|c|c|c|}
\hline Particle Size $(\boldsymbol{\mu})$ & Calculated Settling Velocity (ft./s) & $\begin{array}{c}\text { Recommended Transport } \\
\text { Velocity (ft./s) }\end{array}$ \\
\hline 9 & 0.0000526 & 0.000105 \\
\hline 48 & 0.0015 & 0.003 \\
\hline
\end{tabular}

\section{Horizontal Pipelines}

Solid-liquid horizontal flow can occur in a number of different flow regimes. ${ }^{17,18,19,20}$ The primary parameters influencing flow regimes are velocity and particle size. The common flow regimes are pseudo-homogeneous suspensions, heterogeneous suspensions, heterogeneous suspensions with sliding beds, and stationary beds. Pseudo-homogeneous suspensions occur at high velocities with small particles. The particles move at the same velocity as the fluid with a uniform distribution across the pipe. With slower velocities and larger particles, heterogeneous suspensions occur. The concentration of particles across the pipe is not uniform, and the particle velocity is slightly less than the fluid velocity. At low velocities with large particles, a heterogeneous suspension with a sliding bed occurs. Particles in upper part of the pipe are in suspension and move with the liquid, while particles in the bottom of the pipe form a bed of solids which moves at a slower, uniform rate. At very low velocities with large particles, a stationary bed occurs. The upper part of the pipe contains a suspension, while the lower part contains a deposit, the surface layers of which move.

The conditions at which sliding and stationary beds occur are of interest because these conditions are normally undesirable. A sliding bed can cause substantial pipe abrasion. Sliding and stationary beds lead to low transport efficiencies. The transition between a heterogeneous suspension and a heterogeneous suspension with a sliding bed is often called the deposition velocity or re-suspension velocity, depending on whether the velocity is decreasing or increasing. ${ }^{17}$ The axial velocity in a transfer line should be greater than the deposition velocity or re-suspension velocity. Slurry transfers should occur as heterogeneous suspensions. ${ }^{15,21}$

One correlation frequently employed to calculate minimum transport velocities (i.e. for heterogeneous suspensions) in horizontal pipelines is the Durand equation. ${ }^{14,15,22}$ The correlation was developed for coarse particles, and it does not account for differences in particle size. Equation [5] describes the correlation

$$
\mathrm{v}_{\mathrm{t}}=\mathrm{F}[2 \mathrm{~g}(\mathrm{~s}-1) \mathrm{D}]^{1 / 2}
$$


where $\mathrm{v}_{\mathrm{t}}$ is the minimum transport velocity, $\mathrm{F}$ is an empirical constant that varies between 0.4 and 1.5, $\mathrm{s}$ is the ratio of particle density to fluid density, and $\mathrm{D}$ is the pipe diameter. Using a value of 1.5 for $\mathrm{F}, 1.87$ for $\mathrm{s}$, and 1 inch for the pipe diameter, the calculated minimum transport velocity is $3.2 \mathrm{ft} / \mathrm{sec}$. This correlation does not enable one to calculate the transition between a heterogeneous suspension with a sliding bed and a stationary bed.

Wasp ${ }^{14}$ added a correction to the Durand equation to account for the influence of particle size $\left(d_{p}\right)$. Using this correction, the modified Durand equation is described by equation [6].

$$
\mathrm{v}_{\mathrm{t}}=\mathrm{F}[2 \mathrm{~g}(\mathrm{~s}-1) \mathrm{D}]^{1 / 2}\left(\mathrm{~d}_{\mathrm{p}} / \mathrm{D}\right)^{1 / 6}
$$

This correlation does not enable one to calculate the transition between a heterogeneous suspension with a sliding bed and a stationary bed. Using this correlation, the required transport velocity is $0.86-1.4 \mathrm{ft} / \mathrm{s}$.

Turian et. al reviewed a collection of 864 experimental critical velocity data and developed the following correlation

$$
\mathrm{v}_{\mathrm{t}}=[2 g D(s-1)]^{0.5}(1.7951) C^{0.1087}(1-C)^{0.2501}\left\{\frac{D \rho[g D(s-1)]^{0.5}}{\mu}\right\}^{0.00179}\left(\frac{d_{p}}{D}\right)^{0.06623}
$$

where C is mass fraction. ${ }^{23}$ Using there correlation, one calculates a transition velocity of 1.6 $1.8 \mathrm{ft} / \mathrm{s}$.

Table 19 summarizes the results. When these transport velocities are compared with the velocity in the MCU pipe $(1.4-3.5 \mathrm{ft} / \mathrm{s})$, it shows that transport of the sodium oxalate particles is credible.

Table 19. Transition velocity calculation (ft/s)

\begin{tabular}{|c|c|c|}
\hline Correlation & $\mathbf{v}_{\mathbf{t}}(\mathbf{9} \boldsymbol{\mu})$ & $\left.\mathbf{v}_{\mathbf{t}} \mathbf{( 4 8} \boldsymbol{\mu}\right)$ \\
\hline Durand & 3.2 & 3.2 \\
\hline Wasp & 0.86 & 1.4 \\
\hline Turian et. al. & 1.6 & 1.8 \\
\hline
\end{tabular}

Since the slurry is composed of a mixture of particle sizes, the fine particles that are easily suspended will reduce the settling rate of the coarse particles and thereby reduce the minimum transport velocity. 


\subsection{Conclusions}

Solids have been found in various points in the MCU system. Solids are inherently inimical to the smooth functioning of MCU and therefore must be prevented from forming in appreciable quantities. From the results of analyses from multiple points at MCU, the following chain of events are the likely cause of the process upset:

- $\quad$ super saturation of the salt feed, in conjunction with the oxalate added from ARP cleaning precipitates solids in the SSFT

- $\quad$ agitation of the SSFT mobilizes the oxalate, and possibly aluminosilicate solids

- eventually, enough solids (oxalate and possibly aluminosilicate) accumulate in the first few extraction contactors such that a hydraulic upset occurs

- the hydraulic upset causes salt feed/DSS as well as oxalate solids to migrate through the organic output in extraction contactor \#1, into the scrub contactor\#2

- the hydraulic upset eventually forces caustic aqueous into the strip contactor\#7, elevating the $\mathrm{pH}$ in the SEHT to unacceptable levels

- attempts to clean with water and nitric acid fail in the extraction contactor\#1 due to poor drainage (the drain line was partially plugged with solids) and the large volume of solids

- attempts to clean the scrub contactor with water and nitric acid fail due to large volumes of solids

- addition of acidic material from the CDT to the SEHT succeeds in lowering the $\mathrm{pH}$ in the SEHT, but at the cost of generating solids (which may or may not be transient)

There are still several items on which to speculate.

- Were the aluminosilicate solids in the extraction contactor\#1 drain pipe from the mobilization of solids from the SSFT, or were they from previous deposition of solids. The curious disparate results of having mainly oxalate solids in the extraction contactor and mainly aluminosilicate solids in the extraction drain pipe is not easily explained and may be due to the aluminosilicate solids being present before the oxalate precipitation issue was initiated.

- Other than the mechanical agitation of the SSRTs, was there an additional trigger (time or oxalate concentration or temperature) that triggered the oxalate precipitation.

There were 53 recommendations for improving operations identified in a SRR document. ${ }^{24}$ Some additional considerations or additional details are provided below as recommendations.

- From this point on, IC-Anions analyses of the DSSHT should be part of the monthly routine analysis in order to spot negative trends in the oxalate leaving the MCU system. 
Care must be taken to monitor the oxalate content to watch for sudden precipitation of oxalate salts in the system.

- Conduct a study to optimize the cleaning strategy at ARP-MCU through decreasing the concentration or entirely eliminating the oxalic acid.

- The contents of the SSFT should remain unagitated. Routine visual observation should be maintained to ensure there is not a large buildup of solids. As water with agitation provided sufficient removal of the solids in the feed tank, it should be considered as a good means for dissolving oxalate solids if they are found in the future.

- Conduct a study to improve prediction of oxalate solubility in salt batch feed materials. As titanium and mercury have been found in various solids in this report, evaluate if either element plays a role in oxalate solubility during processing.

- Salt batch characterization focuses primarily on characterization and testing of unaltered Tank 21H material; however, non-typical feeds are developed through cleaning, washing, and/or sump transfers. As these solutions are processed through MCU, they may precipitate solids or reduce performance. Salt batch characterization and testing should be expanded to encompass a broader range of feeds that may be processed through ARPMCU. 


\section{Appendix A - Unusual Observations in the CSEM Analyses}

A number of CSEM samples were analyzed by CSEM, from various points at MCU. While the bulk of the results inferred the presence of oxalate and aluminosilicate, and sometimes titanium oxides, there were some unusual observations for a minority of the sample points. These are presented here.

\section{Iron-Chromium-Nickel or Iron-Chromium-Manganese}

Most of the CSEM samples (extraction contactor, scrub contactor, extraction contactor drain line and the Tank 49H VDS sample) showed 1-3 sample points that registered either an IronChromium-Nickel or Iron-Chromium-Manganese pattern (Figure 19). These peaks appeared together and are attributed to stainless steel fragments.

Figure 21. Typical Peak Attributed to Stainless Steel Fragments

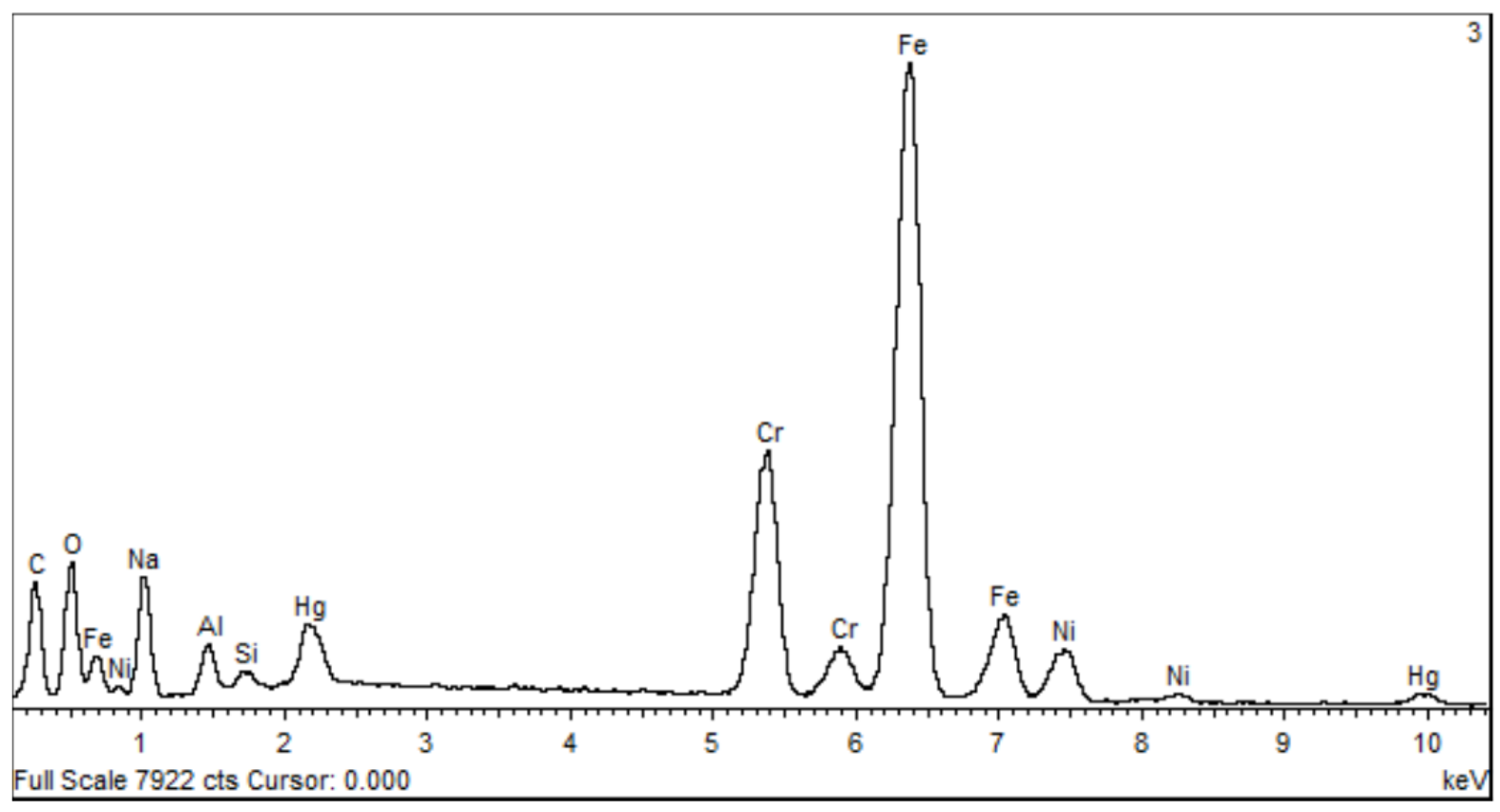




\section{Mercury}

Some of the CSEM samples (scrub contactor, extraction contactor drain line and the Tank $49 \mathrm{H}$ VDS sample) showed 1-3 sample points that registered for mercury (Figure 20). It is unknown at this time what form the mercury is in, or what compound, or why it is there.

Figure 22. Typical Peak Attributed to Mercury

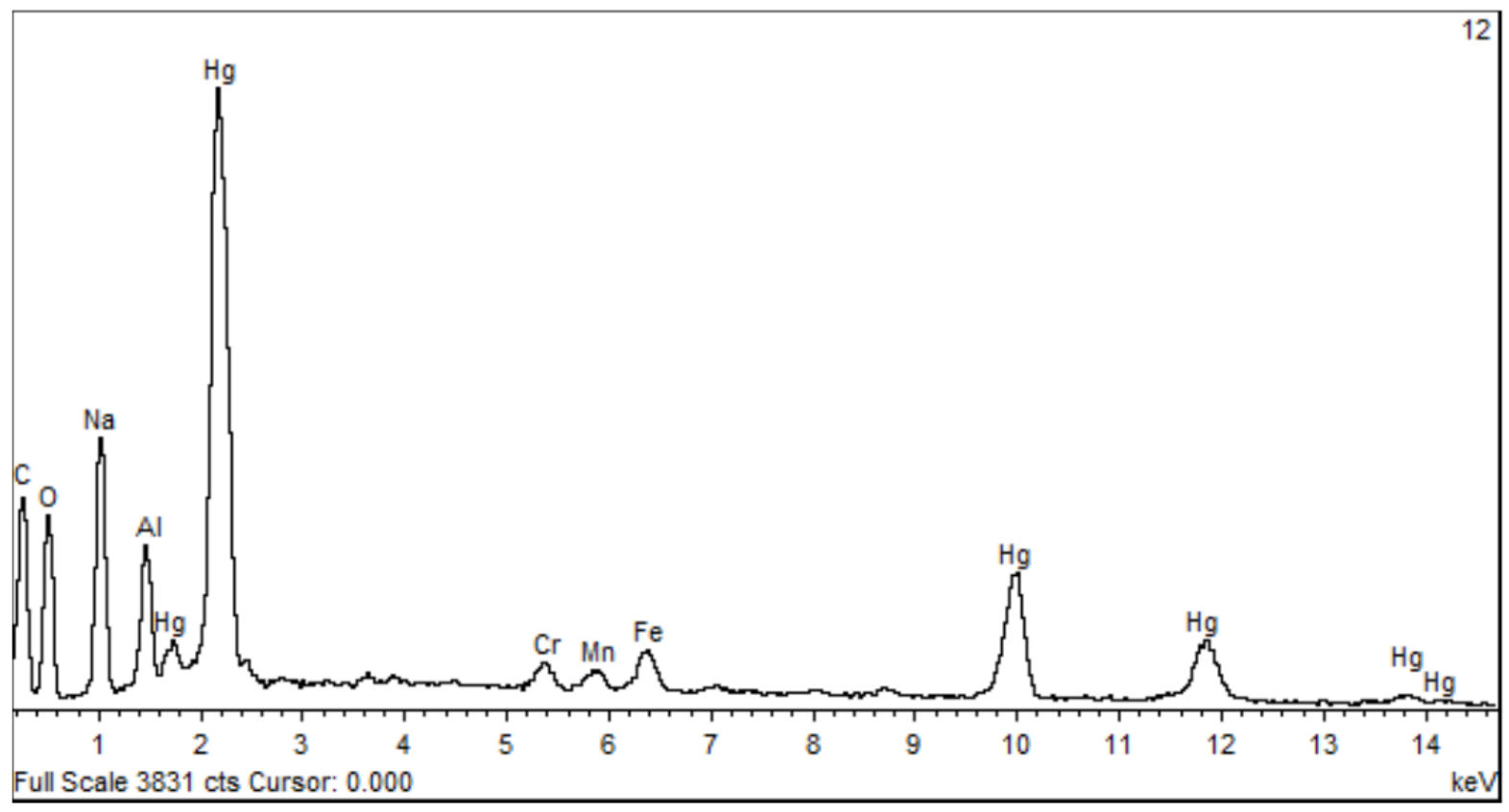




\subsection{References}

${ }^{1}$ T. B. Peters, F. F. Fondeur, K. M. L. Taylor-Pashow, "Results from the Salt Disposition Project (SDP) Next Generation Solvent (NGS) Demonstration Plan”, SRNL-STI-2014-00101, April 2014.

${ }^{2}$ Q. L. Nguyen, X-TTR-H-00026, Rev. 0, July 22, 2013.

${ }^{3}$ T. B. Peters and A. L. Washington, II, F. F. Fondeur. "Task Technical and Quality Assurance Plan for Routine Samples in Support of ARP and MCU”, SRNL-RP-2013-00536, Rev.1, May, 2014.

${ }^{4}$ T. B. Peters, “Salt Batch 7 Operations”, ELN A4571-00084-05.

${ }^{5}$ Savannah River National Laboratory, “Technical Report Design Check Guidelines”, WSRCIM-2002-00011, Rev. 2.

${ }^{6}$ D. L. McWhorter, "Blend Evaluation for Tank 49 Feed for ISDP Salt Batch 7-A May 2014”, X-ESR-H-00661, May 1, 2014.

${ }^{7}$ T. B. Peters, “Analysis of Strip Effluent Hold Tank and Contactor Drain Tank Samples”, SRNL-L3100-2014-00088, May 6, 2014.

${ }^{8}$ C. J. Martino, D. T. Herman, J. A. Pike, T. B. Peters, “Actinide Removal Process Sample Analysis, Chemical Modeling, and Filtration Evaluation”, SRNL -STI-2013-00700, June 2014.

${ }^{9}$ L. N. Oji, “Analyses of Salt Solution Feed Tank Solids and Supernate”, SRNL-L3100-201400133, rev. 0, June 19, 2014.

${ }^{10}$ M. S. Hay, "OLI Modeling of Strip Effluent Hold Tank and Contactor Drain Tank Solutions", SRNL-L3100-2014-00092, May 7, 2014.

${ }^{11}$ A. G. Garrison, "Evaluation of the Impact of Increasing Sodium in the Salt Batch Feed to ARP, MCU, Tank Farm, and Downstream Facilities“, X-ESR-G-00039, July 22, 2014.

${ }^{12}$ D. T. Herman, F. M. Pennebaker, "SRNL Recommendations for Solids Recovery in MCU”, SRNL-L3100-2014-00137, June 19, 2014.

${ }^{13}$ G. W. Govier and K. Aziz, The Flow of Complex Mixtures in Pipes, Malabar: Krieger, 1972, p. 468.

${ }^{14}$ A. W. Etchells, "Mixing and Fluid Flow Fundamentals for Defense Waste Processing at Westinghouse Savannah River Corp.”, August 1994.

${ }^{15}$ N. I. Heywood, “Stop Your Slurries from Stirring Up Trouble”, Chem. Eng. Prog., vol. 95, no. 9, pp. 21-41, 1999. 
${ }^{16}$ I. C. Walton, "Eddy Diffusivity of Solid Particles in a Turbulent Liquid Flow in a Horizontal Pipe”, AIChE J., vol. 41, no. 7, pp. 1815-1820, 1995.

${ }^{17}$ D. M. Newitt, J. F. Richardson, M. Abbott, and R. B. Turtle, "Hydraulic Conveying of Solids in Horizontal Pipes”, Trans. Instn. Chem. Engrs., vol. 33, pp. 93-110, 1955.

${ }^{18}$ W. Parzonka, J. M. Kenchington, and M. E. Charles, "Hydrotransport of Solids in Horizontal Pipes: Effects of Solids Concentration and Particle Size on the Deposit Velocity", Can J Chem Eng, 59, 291 - 296 (1981).

${ }^{19}$ T. C. Aude, N. T. Cowper, T. L. Thompson, and E. J. Wasp, "Slurry Piping Systems: Trends, Design Methods, Guidelines", Chemical Engineering, June 28, 1971, pp. 74-90.

${ }^{20}$ Raffi M. Turian and Tran-Fu Yuan, "Flow of Slurries in Pipelines", AIChE Journal, 23, 232243 (1977).

${ }^{21}$ A. W. Etchells, "Slurry Handling Problems in the Process Industries” in P. Ayazi Shamlou, Ed., Processing of Solid-Liquid Suspensions, Boston: Butterworth-Heinemann, 1993.

${ }^{22}$ C. A. Shook, "Slurry Pipeline Flow", in P. Ayazi Shamlou, Ed., Processing of Solid-Liquid Suspensions, Boston: Butterworth-Heinemann, 1993

${ }^{23}$ R. M. Turian, F.-L. Hsu, and T.-W. Ma, "Estimation of the Critical Velocity in Pipeline Flow of Slurries”, Powder Technology, vol. 51, 1987, pp. 35-47

${ }^{24}$ R. H. Spires, "Solids Precipitation Event in MCU Causal Analysis and Recommendations from Solids Recovery Team”, X-ESR-G-00041, August 13, 2014. 


\section{Distribution:}

K. H. Subramanian, 241-156H

J. R. Vitali, 241-156H

M. T. Keefer, 704-56H

E. J. Freed, 704-S

D. J. Martin, 241-152H

B. A. Gifford, 704-56H

R. E. Edwards, Jr., 766-H

K. D. Harp, 766-H

A. R. Shafer, 241-197H

H. H. Elder, 704-24S

T. T. Le, 241-197H

D. C. Sherburne, 704-S

J. W. Ray, 704-S

C. K. Chiu, 704-27S

S. T. Isom, 241-197H

S. C. Smith, 704-27S

S. A. Utlak, 704-16S

S. L. Marra, 773-A

F. M. Pennebaker, 773-42A

T. B. Brown, 773-A

C. C. Herman, 773-A

E. N. Hoffman, 999-W

T. B. Peters, 773-42A

C. A. Nash, 773-42A

L. N. Oji, 773-42A

A. L. Washington II, 773-42A

C. J. Coleman, 773-A

P. R. Jackson, 703-46A 